\title{
Analyzing the Response of Urban Design Plans to the Emerging Drivers in the Contemporary Urban Environment of US Cities: A Comparative Study
}

\author{
Firas Al-Douri \\ International University of Sarajevo
}

This research examines the substantive content of two urban design plans to assess the extent to which their goals were translated into high-coverage design aspects across the tiers of the design hierarchy. The results showed that both plans have failed to consider design and sustainability as overarching crossscale elements. The emerging drivers were neither explicitly emphasized nor reflected in the plans' themes and policies. The translation of the plan goals into design themes, focus areas, and high-coverage design aspects has involved many discrepancies due to low coverage of the related design aspects and to the approach of the plan's development.

Keywords: urban design plans in US cities, urban design practice, plan content, downtown urban design plans, plan evaluation

\section{INTRODUCTION}

\section{Research Background}

Urban design gives form and definition to the full spectrum of cultural, ecological, political, social, and aesthetic forces that shape the built environment and the public realm (Mugavin, 1992; A1A, 2005). In current practice in US cities, there is a discrepancy between what urban design should be and what it is. The plans that are developed are often applied as a reactive intervention after functional, aesthetic, or economic failure, and they lack adequate coverage of essential design aspects that would normally be considered as central to the role of urban design in shaping the urban environment (Gosling and Gosling, 2003; Lang, 1994; Southworth, 1989). In UK cities also, the plans were poor in fundamental design considerations and few plans considered a strategic role of urban design in shaping future urban forms at the macro or district-wide level (Paterson, 2012; Punter \& Carmona, 1996).

The recent wake of the global economic crisis has created a space for reflection on urban design strategies. Downtowns and city centers in the US have undergone dramatic changes that resulted from the rapidly changing economy, shifting demographics, and evolving community values. Those changes have combined to generate a demand for a new kind of environment and a gradual reclamation of their roles as economic engines and socio-cultural centers for their regions ( $\mathrm{Hu}, 2013$; Brown et al, 2014). City officials, community leaders, and developers have been recently calling for bold initiatives that reflect a sense of confidence in urban living and the role of downtowns. In response, urban designers have been searching for new design models, methods, and tools (Hu 2013; Brown et al, 2009; Bullivant, 2012). The role, scope, and dimensions of urban design practice have been widening and driven by the imperatives of 
urban design response to contemporary challenges (Carmona et al 2010; Oliviera \& Pinho 2010; Feliciotti et al, 2015; Banerjee \& Loukaitou-Sideris, 2011).

Thus, a change in thinking is occurring as to what urban design needs to achieve (Mugavin, 1992). Besides the strong concern of urban design with the visual and aesthetics considerations, there is a growing concern with the emerging contemporary issues and drivers that influence design decisionmaking such as equity, livability, health, walkability, and socio-cultural diversity (Punter 2007; Inam 2011; Linovski \& Loukaitou-Sideris, 2013; Mugavin, 1992).

Within this refocusing, there are questions and shifting notions about what goals urban design needs to achieve, what constitutes the plans' content, and with what design aspects and scales of intervention those goals could be achieved. In particular, there are questions about the plans' guiding themes and focus areas that are emerging from new political, social, cultural, and ecological conditions (Loukaitou-Sideris, 2012, Bullivant, 2012; Linovski \& Loukaitou-Sideris, 2013; Al-Douri, 2010; Punter, 2007; Mugavin, 1992).

Thus, there is an increasing attention to the evaluation of plans' content and quality, which provide an empirically accurate and theoretically relevant view of planning practice (Palermo \& Ponzini, 2012; Laurian et al, 2010). Yet, very few studies have critically examined how the substantive content of urban design plans responds to these new drivers. They were either focused on examining the impact of computational tools' usage on the plan content (Al-Douri, 2006, 2010, 2013) or were pursued on plans that were developed prior to the rising of the effects of those new conditions on the urban environment (Southworth \& Southworth, 1973; Southworth, 1989; Punter \& Carmona, 1994).

\section{Research Problem}

Urban design is the synthesis of the elements and aspects of urban form across scales to achieve functional, cognitive, social, and environmental goals. It requires articulating a clear vision based on a precise analysis of the process and drivers of recent geopolitical and social transformations that influence design decision-making.

In current urban design practice in US cities, however, the content of plans that are developed is limited in scope, scale, and design guidance as follows:

1. The plan goals, guiding themes, and focus areas are focused only on one or a set of design considerations such as aesthetics, sustainability, environment, or transportation.

2. The design aspects that constitute the plan content do not reflect or match all the plan goals, guiding themes, and focus areas.

3. The design aspects do not offer hierarchical design guidance for intervention at various scales of the urban environment (Brown et al, 2009; Linovski \& Loukaitou-Sideris, 2013).

This is due, in part, to the strong concern that planning authorities typically show for aesthetics, townscape, and public-private partnership in their urban design practices. Urban design decisions and policies are often made without consideration to those drivers and are being eclipsed by an emphasis on the speed rather than the quality of decision-making (Kelbaugh, 1994; Paterson, 2012; Punter, 2007; Inam, 2011; Linovski \& Loukaitou-Sideris, 2013). This has raised serious questions about the adequacy of those urban design and control tools (Harfield, 2010).

There is a grounded belief that evaluation in urban design and planning can contribute to better planning practice and advance knowledge in urban design (Mugavin, 1992; Oliveira \& Pinho, 2010). However, very few studies have critically examined the substantive content of urban design plans. Research is needed to better understand the plan content and to assess the extent to which such content has matched the plan's goals, guiding themes, and focus areas. This task could be pursued through an examination of selected cases of contemporary urban design plans in US cities.

\section{Research Objectives and Questions}

The research objectives are as follows:

1. Assessment of the extent to which the plan's guiding themes and focus areas (guiding themes hereafter) have addressed the drivers shaping contemporary urban environments. 
2. Assessment of the extent to what the plan's content has reflected those guiding themes,

3. Assessment of the extent to what the plan's content has offered hierarchical design guidance.

To attain these objectives, the research has addressed the following questions:

1. What design aspects constitute the plan's content and how do they relate to the plan's guiding themes?

2. What drivers should be considered in contemporary urban design practice?

3. What constitutes the hierarchical design guidance in urban design plans?

Case studies of recent urban design plans may help to gather evidence regarding the research questions and objectives. This research used the comparative case study approach to examine the content of two recent urban design plans, San Diego Downtown Community Plan 2006 in San Diego, CA, and Imagine Downtown Plan 2009 in Atlanta, GA.

\section{RESEARCH METHODS AND DATA COLLECTION}

This research is a comparative case study that used quantitative and qualitative content analysis to examine two urban design plans in US cities and address issues of internal and external validity. Content analysis provides a widely accepted and appropriate research method for systematically assessing the symbolic content of urban design plans within the context of the development process (Norton, 2008; Zammit, 2015; Carmona, 2007). Although these plans may vary in terms of their physical attributes, history, political landscape, and culture, each provides new insights and demonstrates the range of strategies adopted to achieve its desired downtown goals (City of Portland, 2007).

This research was pursued in three phases: literature review, content analysis, and analysis of empirical findings. Each phase is briefly discussed in the following subsections (2.1-2.3).

\section{Literature Review}

A review of the related literature has been pursued to construct a conceptual model to which the empirical results were compared. The literature review was focused on reviewing secondary sources that have critically examined the substantive content of urban design plans such as Punter \& Carmona (1994, 1996, 1997a, 1997b); Carmona, Punter, and Chapman (2002); Turner, (1993, 1994), Southworth (1989), and Linovski \& Lokaitou-Sideris (2013). Also, it reviewed the studies that discussed the emerging drivers of contemporary urban design practice in US cities such as Banerjee \& Loukaitou-Sideris (2011), Bullivant (2012), and Brown et al $(2009,2014)$.

\section{Content Analysis}

This phase was focused on developing a content analysis evaluation protocol to measure and assess the content and coverage of the plans. The primary concern of the development process was that the categories are precise in meaning, unambiguous, complete, and do not overlap or duplicate one another (Oliveira \& Pinho, 2010; Norton 2008). In urban design, problems of content analysis are twofold: first, where one design policy ends and another begins poses some definitions problems (Punter \& Carmona, 1996). Second, some design aspects may not be addressed explicitly, but maybe implicitly within other design categories or scales of design control, or addressed using alternative terms that convey the same meaning (Punter et al, 1994; Norton, 2008; Zammit, 2014). As a result, attempts to measure quantitatively only the number of design aspects may result in serious measurement errors.

To address those concerns, the design of the evaluation protocol has adopted three strategies for developing suitable categories and recording instructions. First, it has followed the method-driven approach as described by Krippendorff (2004) which involves the application of known analytical procedures to areas previously explored by other means (Krippendorff 2004). Second, the structure and development of the coding scheme have followed the prior research-driven approach as described by Boyatzis (1998) which lends itself to what Strauss and Corbin (1999) called "axial coding" in clustering categories to enhance the reliability of the collected data and the external validity of findings. Third, it was grounded within a clear theoretical framework that was extracted and collated from related literature. 
The framework involved a broad spectrum of the functional, visual, and environmental dimensions of the urban environment across scales and consisted of urban design aspects that are elaborated with a relevant set of detailed design elements (Punter \& Carmona, 2007; Zammit, 2014).

To build a framework of the design aspects, this research has reviewed the studies that had attempted to list those aspects such as Urban Task Force (1999), Cowan (2002), CABE (2005), and Carmona et al (2002). Hence, it has adopted the list of design aspects defined by Carmona et al (2002), an advanced form of the list applied by Punter and Carmona (1994, 1996, 1997a, 1997b) in prior research on design content in the US and UK cities. Its significance stems from its comprehensive and flexible approach that represents the plan's constituent policies, aspects, and elements across scales (Carmona, Punter and Chapman, 2002).

Design aspects that typically comprise the content of urban design plans consist of two groups: core aspects and detailed, subject-specific aspects (Carmona et al, 2002; Turner, 1993). They result from disaggregating urban design policies into individual design aspects and subsequently into their constituent design elements. They address multiple disciplines of the urban environment and establish a solid framework that may be used in the assessment of the plan's content (Zammit, 2014). These aspects are townscape, urban form, public realm, mixed-use and tenure, connections and movements, conservation areas, and sustainable urban design (Carmona et al, 2002).

To avoid the limitations of content analysis that is pursued exclusively by computer (Krippendorff, 2004), the analysis was pursued in both qualitative and quantitative approaches with computational and manual methods in three phases. The first phase was a quantitative, computational content analysis of the plan documents that were obtained in the digital (. pdf) format using the NVivo (version 10) data analysis software package. The results were imported into the Microsoft Excel worksheet that included all design aspects and their constituent elements for an initial overview of the plan goals and guiding themes.

The second phase was a qualitative analysis of the plan documents to assess the extent to which the plan has covered the elements of urban design. The assessment and a categorical classification of any element were determined after reading and evaluating the plan's context, goals, and themes. This was critical for two reasons: first, viewing an element in isolation could imply a categorical association that does not match the actual document context; second, the same element may fall into multiple categories given a different context (Zammit, 2014; Krippendorff, 2004; Norton, 2008). The third phase involved multiple readings of the plan document such that only elements that are related to the research questions and plan goals, themes, and context were carefully examined and assessed.

As with all evaluation methodologies, the primary issues regarding the accuracy of content analysis of urban design plans are measurement validity and assessment reliability (Norton, 2008). The clarity and assessment reliability were insured through five measures. First, the content analysis process and tool were well-grounded in substantive theories related to the phenomenon to be measured (Devillis, 1991). Second, they were complemented with a well-formulated definition of the design aspects/elements (Norton, 2008). Third, the coding scheme has followed a previously adopted model and used categories that rely on conceptualizations that have proven successful elsewhere. This strategy could greatly enhance reliability and has a better chance of drawing on and contributing to existing knowledge (Krippendorff, 2004). Fourth, grouping the elements into design aspects that accurately describe their meaning and uses provided a balanced distribution and increased the content validity and structural validity of the content analysis (Zammit, 2014; Krippendorff, 2004). Finally, the employment of fewer but exhaustive design aspects in the analysis process helped reduce the variations between the terms, making it easier to analyze statistically (Zammit, 2014).

\section{Assessment of the Extent of Design Aspects Coverage}

The evaluation protocol has employed the designed Pro-forma to score the frequency and intensity of the units of analysis (recording units) which were the urban design elements that constitute each design aspect. Rather than focusing on the elements' frequency, assessment of the coverage of each design element was determined based on the extent to which it was controlled with concrete design control measures in the plan. This qualitative component of the content analysis is critical since a low-frequency 
element might still be significantly covered if the entire plan or plan section was meant to control and shape that element (Zammit, 2014; Krippendorff, 2004). No one element deserved more weight than another did.

The coverage of the design elements was assessed using a scale of three levels: no coverage, minor coverage, and significant coverage. A design element was assessed with no coverage level if there was no evidence whatsoever of its design, analysis, and coverage of the locality in the plan policies. A design element was assessed with minimum coverage if it was addressed but tends to be largely descriptive without clear design principles, measures or guidelines to comprehensively shape its design attributes and tailor them to the locality. A design element was assessed with significant coverage if it was addressed effectively through design policies, measures, and guidelines to shape its attributes in response to the local conditions. The assessment was made after multiple readings of the plan text and drawings as described in section 2.2 .

The extent of coverage of each design aspect was assessed as high, medium, or low, according to the percentage of its constituent elements that were covered with significant coverage. These levels and their respective assessment criteria are illustrated in Table 1 as groups A (66\% - 100\%), B (33\% - 65.99\%), and C $(0 \%-32.99 \%)$, respectively (See Table 1$)$. The extent of design aspects' coverage was assessed in its consistency with the plan guiding themes and goals, the conceptual model, and findings of recent studies.

\section{TABLE 1 \\ MAXIMUM AND MINIMUM LIMITS OF THE VARIOUS COVERAGE LEVELS OF DESIGN ASPECTS}

\begin{tabular}{|c|l|c|c|}
\hline \multirow{2}{*}{ Group } & \multirow{2}{*}{ Definition of overall coverage } & \multicolumn{2}{|c|}{$\begin{array}{c}\text { Criteria: Percentage of } \\
\text { elements addressed with } \\
\text { significant coverage }\end{array}$} \\
\cline { 3 - 4 } & & Minimum & Maximum \\
\hline A & Design aspects addressed with high coverage & 66 & 100 \\
\hline B & Design aspects addressed with medium coverage & 33 & 65.99 \\
\hline C & Design aspects addressed with low coverage & 0 & 32.99 \\
\hline
\end{tabular}

\section{THE CONTENT OF URBAN DESIGN PLANS: ITS CONSTITUENTS AND DRIVERS}

\section{The Existing and Emerging Drivers Influencing the Plan Content}

In the later decades of the $20^{\text {th }}$ century, the principles of urban design consensus that emerged since the 1950s in Europe and North America had to be adapted to an increasingly complex urban agenda. This agenda includes new emerging large-scale forces, concerns, and trends such as urban sustainability, innovations in communications and IT, and the erosion of the public realm among others (Kelbaugh, 1994; Paterson, 2012; Lloyd-Jones, 2006; Feliciotti et al, 2015).

Much contemporary urban design practice, however, overlooks or actively marginalizes the provision for social needs in favor of a commitment to formal outcomes, physical attributes, and architectonics that is driven by increasingly esoteric design and decision-making means (Harfield, 2010; Kelbaugh, 1994). Experts have pointed to the disastrous consequences of such narrowly focused urban design thinking which fails to consider the full complement of forces that shape people's lives namely, environment, traffic, transit, public health, public realm, culture and education, security, and technology (Bullivant, 2012; Brown et al, 2009, Harfield, 2010).

Southworth (1989) reviewed 70 urban design plans for 40 US towns and cities prepared between 1972 and 1989 and compared them to the first generation plans in 1960-72. Those plans revealed some common themes, including more concerns for user needs, more focus on managing the quality and 
character of large areas through policies, standards, and design review, and more emphasis on the assets of the environment (Southworth, 1989; Hu, 2013).

A recent study by Linovski \& Loukaitou-Sideris (2013) provided a critical evaluation of the vision, methods, and content of urban design plans in 21 large North American cities (population over 500,000) and a comparison with earlier generations of plans that were examined in Southworth's studies. The results revealed that recent plans showed a greater interest in transit solutions, sustainability, green design, environmental concerns, and mixed-use but less concern about diversity, equity, and economic development. The plans were primarily dominated by aesthetic concerns and guidelines concerned with the urban form of the city, its buildings, and its public realm, but they made little or no reference to the socio-cultural goals and economic development impacts of urban design actions and failed to respond to diverse and often conflicting needs of different social groups. Despite the considerable developments in computer-based technologies as analytical tools, few of the plans that have been examined offered innovative ways for studying and interpreting the environment (Lehmann, 2006; Linovski \& LoukaitouSideris, 2013, Hu, 2013).

There is a growing interest in a multi-disciplinary, holistic approach to urban design and a widening role and scope of urban design practice. Those changes have been driven by the imperatives of an urban design response to the contemporary drivers that led to the emergence of new approaches, concepts, methods and tools of urban design such as, urban agriculture, urban resilience, new public realm, smart growth, smart eco-cities, green infrastructure, and walkable neighborhoods (Brown et al, 2009, 2014; Bullivant, 2012; Lloyd-jones, 2006; Moor \& Rowland (Eds.), 2006; Lim \& Liu, 2009; Rachel, 2011; Carmona, 2014; Carmona et al, 2010; Loukaitou-Sideris, 2012; Punter, 2007, 2010; Linovski \& Loukaitou-Sideris, 2013; Banerjee \& Loukaitou-Sideris, 2011 (Eds.); Oliviera \& Pinho, 2010; and Hu, 2013). Other drivers are being emphasized in the future downtown urban design such as elder-friendly communities and walkable downtown neighborhoods (Loukaitou-Sideris \& Banerjee, 2011) and the three intertwined public goods drivers: environmental health, vital public realm, and support for the development of creative milieus (Childs, 2010).

As such, contemporary plans should embody principles that integrate economic, physical, social, collaborative, environmental, circulatory, interactive, and safety dimensions of the identity of the place (Bullivant, 2012; Inam, 2011).

\section{The Influence of the Plan's Approach to Design Guidance and Control on Its Content}

There is a variety of substantive and procedural factors that could, directly and indirectly, affect the plan content such as the plan's scale, type, methodology, context, analytical and prescriptive content, and effectiveness of computational tools' usage (Al-Douri, 2010, 2013). Among those factors, the plan's goal, guiding themes, focus areas, and approach to design guidance and control are the most important factors (Turner, 1993, 1994; Paterson, 2012; Punter and Carmona, 1996).

A review of the literature reveals three distinct approaches to design guidance and control that may influence the plan content. The first approach is primarily focused on shaping the urban form with emphasis on a few key design aspects that are central to the role of urban design particularly, aesthetic, functional, and environmental aspects. Some studies that followed this approach, such as By Design: Urban Design in the Planning System and Urban Task force's Towards an Urban Renaissance suggested that the plan content should address specific built form qualities at a range of scales, within a specific spatial territory, typically with a focus on either the physical urban fabric and professional design (Marshall, 2015) and/or the form and character of the public realm (Biddulph, 2012; Urban Task Force, 1999; Llewelyn-Davis \& Alan Baxter \& Associates, 2002; Cowan, 2002). Similarly, ecology-focused studies have considered the urban form and its relation to sustainability as a fundamental overarching theme across design and planning scales (Lehmann, 2006, Oliveira \& Pinho, 2010).

The second approach promotes a broader sense of urban design practice that goes well beyond elevations, aesthetics, and architectural control. Instead, it focuses on urban-wide issues particularly urban form, public realm, urban infrastructure, landscape, and on harnessing their qualities such as scale, density, layout, grain, mobility, and access. Rather than stifling experiment, originality, and innovation, it 
avoids over-prescriptive control and attempts instead to accommodate organic spontaneity, vitality, innovation, and pluralism (Carmona, Punter, \& Chapman, 2002; Punter \& Carmona, 1994, 1997a, 1997b, 1996; Punter 2007; Jaskiewicz, 2013; Turner, 1993, 1994).

The third approach is based on the premise that good quality urban design practice needs to operate at a range of scales simultaneously. It crafts strategic visions for intervention and guidance at the larger metropolitan and regional terrains (Bullivant, 2012; Loukaitiu-Sideris, 2012; Rowley 1994) and subsequently develops a series of alternative options for accomplishing the visions (Brown et al, 2009; Paterson, 2012). Hence, the plan content emerges at the strategic, citywide visioning level, is rooted at the district level, and responds to the particularities of place and local distinctiveness (Chen, 2016; Palerom \& Ponzinin, 2012; Kelbaugh, 1994). This would result in a richer content that consists of a combination of several design elements across scales including local three-dimensional design aspects, architectural design, and quality of open areas

Regardless of their approach, urban design plans and implementation should be predicated on an understanding of the consequences of their constituent policies for the society (Harfield, 2010). The narrow concentration of the first two approaches on policy/strategic and physical design issues respectively may be at the expense of profound analysis and understanding of the area's characteristics that may result in neglecting key social, economic, environmental, and local design issues (Harfield, 2010). Thus, this research has followed the third approach to develop the conceptual model.

\section{The Content of Urban Design Plans: A Conceptual Model}

The conceptual model has defined and related three sets of substantive and procedural elements of urban design plans: guiding themes and focus areas, design aspects, and tiers of design guidance (See Figure 1). In doing so, the model has largely adopted and synthesized the theoretical propositions suggested by Brown et al (2009, 2014), Carmona, Punter \& Chapman (2002), Turner (1993, 1994); Rowley (1994); and Punter (2007) regarding the strategies, aspects, and elements that are required to implement the guiding themes of urban design plans in downtowns and city centers. It has reviewed a variety of studies on hierarchical design guidance in Australia (Mugavin, 1992), Italy (Palermo \& Ponzini, 2012), and China (Chen, 2016).

The conceptual model implies that urban design implementation is built into three core strategies: policies that translate political, social, and environmental values into concrete goals; planning that provides a broad framework for achieving these goals; and place-making that translates these frameworks into the physical environment (Brown et al, 2014). The model, as a result, implies that three-tier hierarchical design guidance would comprehensively address design control across various scales.

An extensive review of downtowns and city centers plans that were recipients of the National AIA award in the Urban and Regional Design category showed that they typically include the following key goals:

1. building a sense of community through creating an inviting public realm,

2. advancing environmental sustainability through smart growth,

3. expanding individual choices through programming and planning,

4. enhancing personal health through promoting walkability, and

5. placemaking through strengthening the sense of district identity (Brown et al, 2009, 2014)

To implement these goals, the plan development should be based on five core principles: enhance livability, create community, expand opportunities, promote equality, and foster sustainability. The conceptual model has connected those principles in a cause and effect relation such that the first two principles would lead to the third and fourth ones. Consequently, the four principles would lead to the fifth principle, i.e. fostering sustainability (Brown et al, 2014). This causal relation has emphasized the role of sustainability as an overarching design principle that blends into all other principles.

The conceptual model has also connected the design aspects to the strategic, intermediate, and detailed tiers of design guidance hierarchy that sets out a coherent, comprehensive, and coordinated vision of environmental design. The first tier consists of core design aspects that deliver the area's spatial strategy and vision and translate political, social, environmental values into concrete goals. It is the 
cornerstone of urban design plans because it helps build a strategic, area/city-wide vision, which provides the foundation on which local, detailed design plans are developed. The second tier consists of aspects that provide design guidance and area-based strategies at an intermediate scale. Those aspects provide a broad framework that articulates a clear physical vision, infuses a strong emphasis on design in the urban environment, and provide a basis for community engagement. The third tier provides detailed, subjectspecific design and development guidance that encourages the use of placemaking principles, architectural skills and design criteria for conservation areas and areas of strong identity and architectural character (Chen, 2016; Palermo and Ponzini, 2012; Brown et al, 2009, 2014; Punter, 2007; Carmona, Punter, and Chapman, 2002; Punter and Carmona, 1996).

\section{FIGURE 1 \\ A CONCEPTUAL MODEL RELATING THE DESIGN ASPECTS, GUIDING THEMES AND FOCUS AREAS, AND TIERS OF DESIGN GUIDANCE IN URBAN DESIGN PLANS}

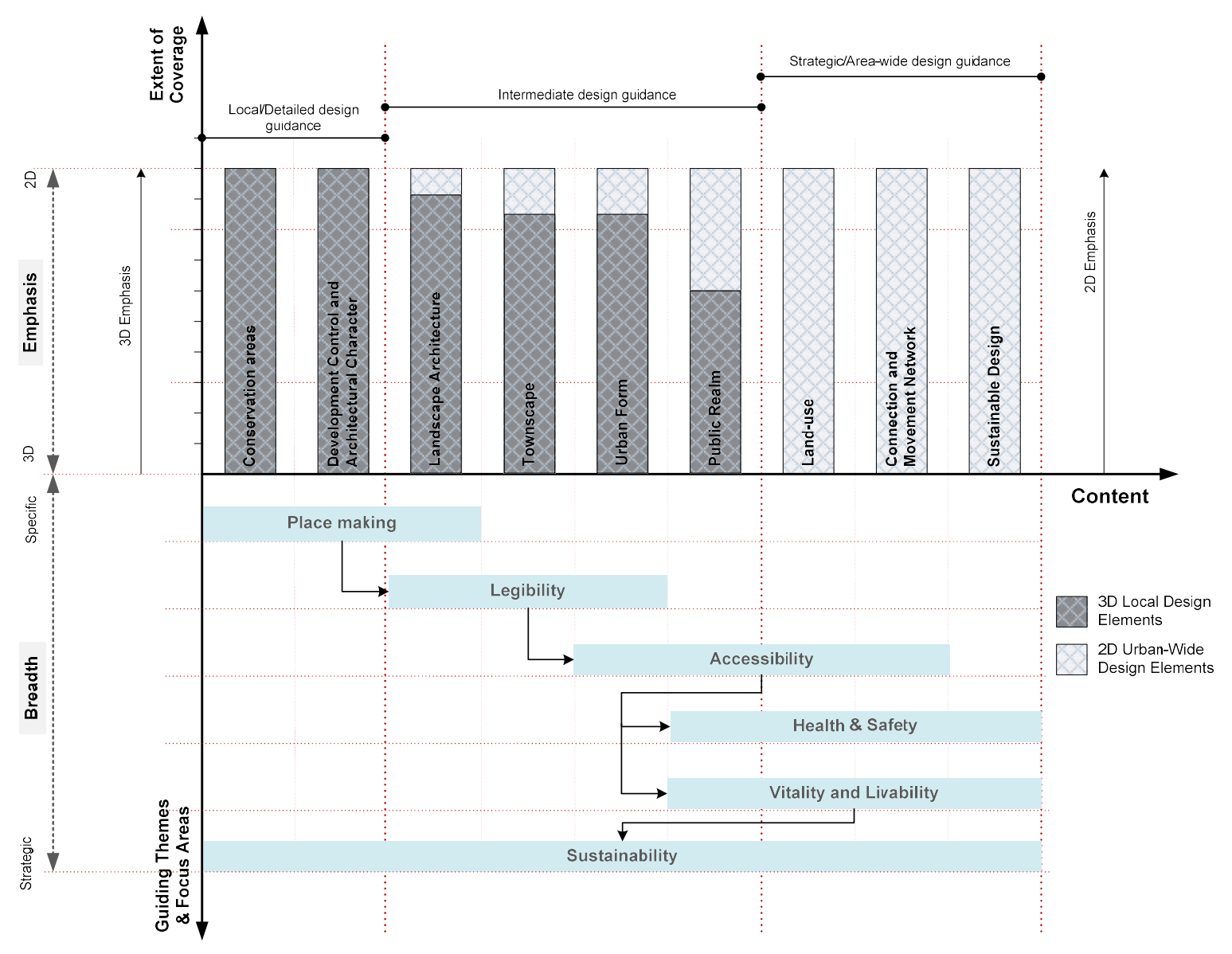

\section{TWO CASE STUDIES OF URBAN DESIGN PLANS}

\section{San Diego Downtown Community Plan (SDDCP)}

The Plan's Background, Goals, and Guiding Themes

San Diego Downtown covers about 1,450 acres and has a population of approximately 20,800 with an additional 5350 residents in group quarters. Following significant redevelopment efforts that attracted a wide range of activities, the Downtown has experienced a renaissance from a state of blight and decline 
in the mid-1970s, which brought new life to older neighborhoods and tourist destinations and led to booming residential growth.

With growth came new challenges such as re-establishing the area's prominence as the center for business and employment, providing amenities and an environment supportive of dense residential populations, maintaining the uniqueness and cultural attributes of the evolving neighborhoods, and conserving historical assets and distinctive attributes (Brown et al, 2014; CCDC, 2006, p. 1-9; Cullingworth \& Caves 2009).

The SDDCP has articulated a vision for the downtown as a center of influence on the Pacific Rim and as the center of regional, economic, residential, and cultural activity with 90,000 residents and nearly 165, 000 jobs and 170,000 employees by 2030 (CCDC, 2006, p. 1-1). The Plan was developed as a tool to establish a policy framework that will shape further development in the pursuit of that vision. It builds on San Diego's "City of Villages" strategy, which calls for curtailing regional sprawl and increased infill development. It serves the following purposes:

1. Establishes land use vision and development policies for downtown,

2. Provides strategies and specific implementing actions that will allow the vision to be accomplished,

3. Allows all public and private development agencies to design projects that will enhance the character of the community, and

4. Provides the basis for detailed plans and implementing programs.

The Plan's eight guiding principles are centered on three main themes: Physical development, Transportation and public facilities, and Community development which combine to create the overarching goal that the plan strives to achieve. Those principles include downtowns' urban image, waterfront setting, physical and symbolic role, and constituent neighborhood connections. Thus, SDDCP was a representative sample of current urban design plans that attempt to re-establish the Downtown's prominence as the center of regional, economic, residential, and cultural activity

FIGURE 2

\section{SAN DIEGO DOWNTOWN COMMUNITY PLAN AND RELATED DOCUMENTS (SDDCP, P. 2-8)}

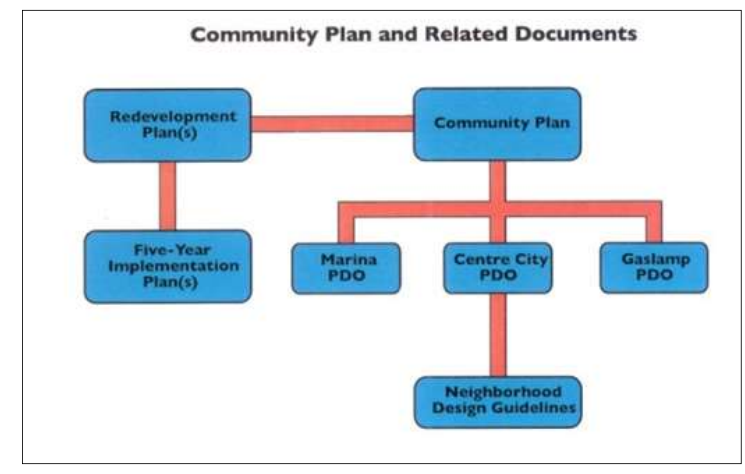

\section{The Development Process and Implementation Tools}

The Plan was based on research and analysis of the existing conditions and trends, the changing regional and local conditions, and new citywide growth management policies. It was the product of twoyear collaboration with the downtown community members and stakeholders structured around issues' identification, vision and goal setting, and alternative analysis and synthesis. The 35 -member steering committee which formulated the planning and design principles was central to the process (CCDC, 2006, p. 2-4).

The Plan is one component of a hierarchical system of plans and development regulations that range from the expression of vision to adopted policy and enforceable building codes and standards 
(See Figure 2). The plan will be implemented through a variety of mechanisms such as zoning regulations, Transfer of Development Rights (TDR) programs for parks and historical resources, capital improvements for specific streetscapes and parks, and neighborhood design guidelines (See Figure 3) (CDCC 2006, p. 14-2).

\section{FIGURE 3 \\ SOME CONSTITUENTS OF SAN DIEGO DOWNTOWN COMMUNITY PLAN (SDDCP)}

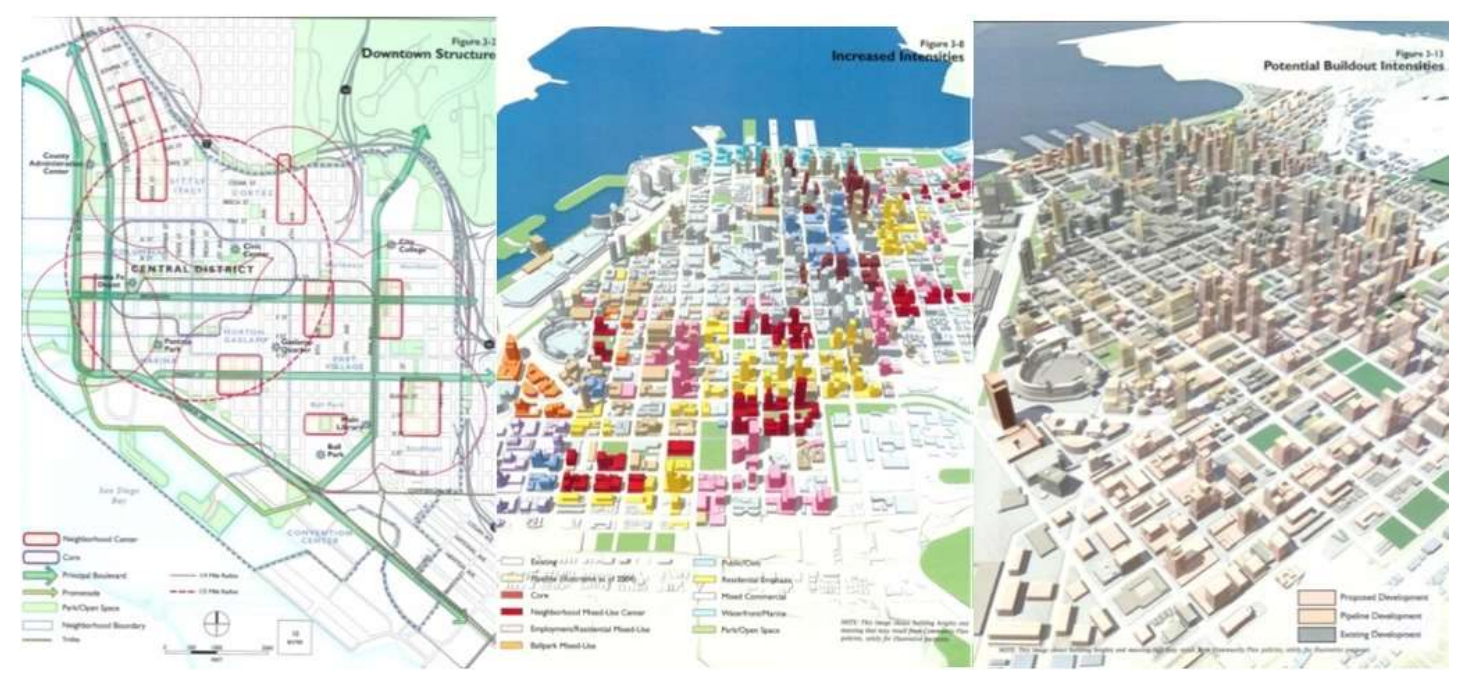

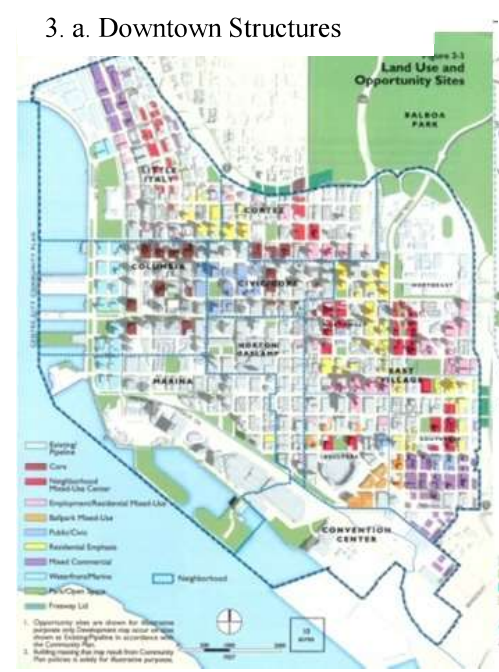

3. d. Land-use and Opportunity Sites

3. b. Increased Intensities

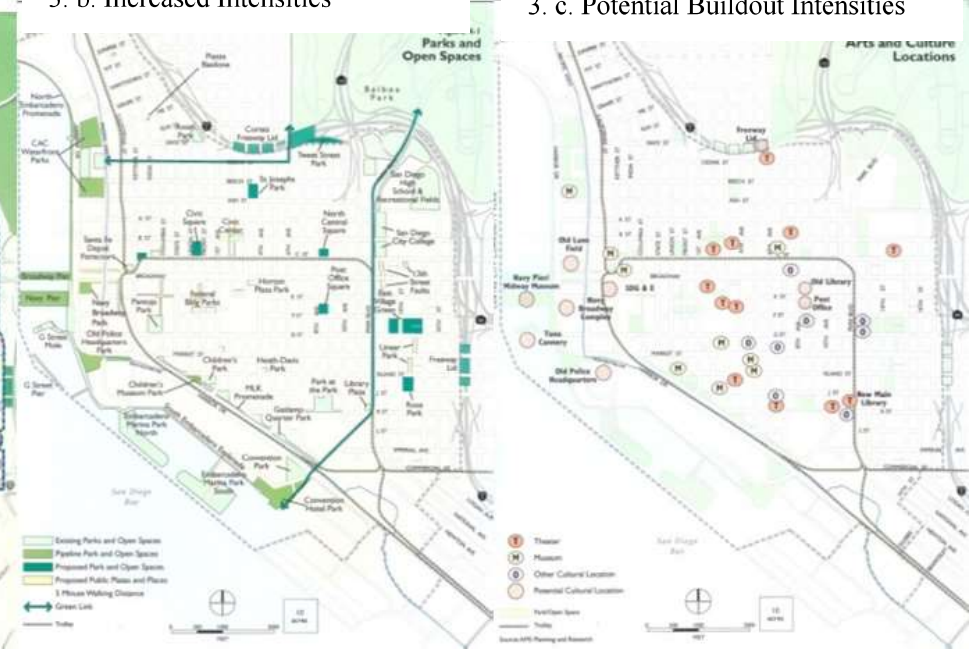

3. e. Parks and Open Spaces

3. f. Arts and Culture Locations

\section{Imagine Downtown, Atlanta, GA (IDA)}

\section{The Plan's Background, Goals, and Guiding Themes}

Downtown Atlanta has seen rapid growth since the 1996 Centennial Olympic Games and over \$3 Billion worth of new investments and development from 2004 through 2009. It added residents and wealth faster than the city as a whole and the surrounding region (Brown et al, 2014). Over 33,000 people live within this densely populated four-square-mile area, which represents a $54 \%$ population increase since 1990 and a 40\% increase since 2004. Additionally, almost four million people visit the area annually for conventions, trade shows, and tourist attractions (CAP, 2009, pp. 1-3). Downtown Atlanta, being the region's most dense concentration of employment, thus serves as the physical and economic 
center for the metropolitan region. It is a symbolic, economic, cultural, and recreational extension of each community in north Georgia.

In the years preceding the original Imagine Downtown plan 2004, several key efforts established area-specific or topic-specific visions that were focused on mixed-use, walkability, and diversity and have generated momentum for new residential, commercial, institutional, and government activities in the center city (Brown et al, 2014). The City, however, has struggled with issues associated with worsening congestion and commuting times, unsustainable real estate economics, higher costs of providing basic services, and tougher competition from other US cities for economic growth. Waldheim (2013) thus described Atlanta as "one that does not have the classical symptoms of the city, it is a landscape of forests

and roads", and suggested instead a significant role for landscape urbanism as a lens that could offer strategies of urban design to the rather fragmented, low-density city (Waldheim, 2013 p.539).

The city sought to develop a vision plan that seeks to affirm and refine recent master plans for Downtown Atlanta with a more detailed and strategic focus to guide future public and private investment in the community. The City's ultimate goal was vision building and the development of a highly sustainable framework for the growth and development of a vibrant and attractive Downtown (CAP, 2009 , p. 1). The plan was meant to complement the other citywide and downtown master plans with a more detailed and strategic focus that would guide the Downtown's future growth.

\section{The Development Process and Implementation Principles}

The development process was centered on three primary topic areas: Growth and Development, Mobility, Livability, and Attractions (CAP 2009, p. 12). It included workshops for five focus areas: growth, mobility, open space, vision, and districts. Those areas have translated into five constituent plans that identified the future development framework; neighborhoods, districts, and emerging priority projects; public space opportunities; and transportation network and improvements to support their implementation and to promote the Downtown's sustainable growth and development (See Figure 4) (CAP, 2009).

The original plan was developed directly from information gathered through an online survey with multimedia imagery, focus area workshops, core team meetings, and stakeholder interviews. The plan's update of 2009 has garnered support and input through the use of three distinct outreach mechanisms: stakeholder interviews, core team dialogue, and public forum (CAP, 2009). To attain its goal, the plan faced a challenge of integrating a variety of dynamic urban systems across scales and interconnecting research results from diverse stakeholders' groups into resilient urban forms that would provide a high quality of life.

The implementation program was based on strategic planning principles that were shaped by the community during the core team meetings, stakeholder interviews, and public forum. Those principles have emphasized the creation of high-quality sustainable development and regulation of private development using zoning and development incentives. 


\section{FIGURE 4}

THE CONSTITUENT PLANS OF IMAGINE DOWNTOWN ATLANTA 2009 (IDA 2009)

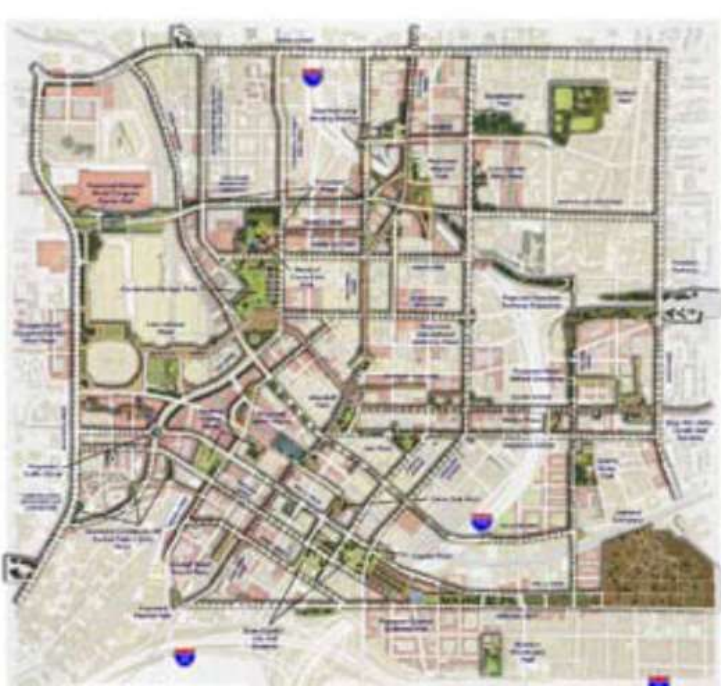

4. a. Public spaces plan

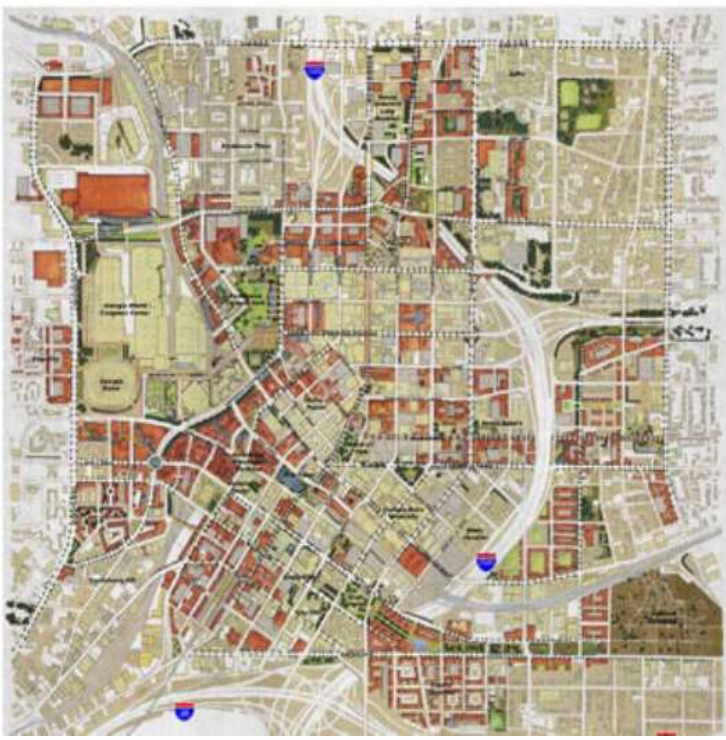

4. c. The Illustrative Plan is a convergence of three plans: Development Framework, Public Spaces, and

Transportation Plans, incorporating goals established in the Imagine Downtown process

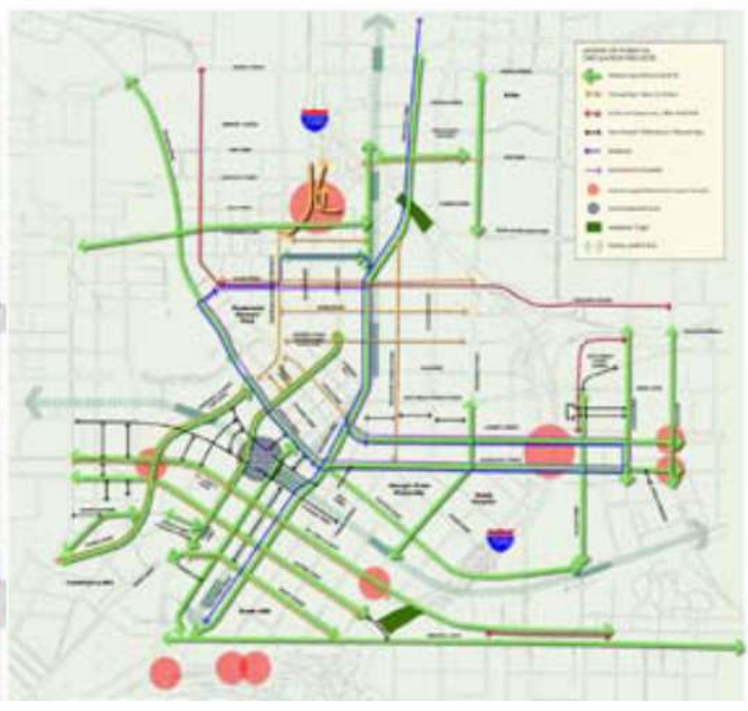

4. b. Transportation Plan

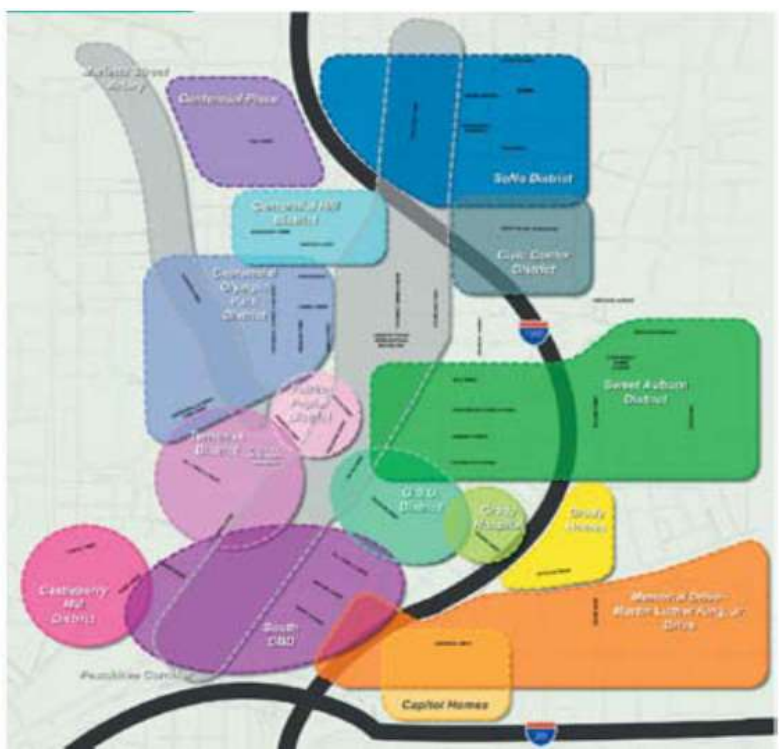

4. d. Neighborhoods and districts 


\section{ANALYSIS AND JUSTIFICATION OF EMPIRICAL FINDINGS}

This section discussed two analytical tasks. In the first, the content analysis results were contrasted with the conceptual model and the findings of recent studies. The second task involved the comparison of the content of both plans and comparing the results to the content of CCAP, an award recipient plan. The results of these tasks have helped to address the research questions and achieving its objectives.

\section{Assessment of the Relation of Design Aspects' Coverage to Plan Guiding Themes \& Goals}

The design aspects were ranked in descending order according to their extent of significant coverage (See Table 2, Figure 6). The coverage of the highest four design aspects [1-4] in both plans appeared to be linked to the guiding themes (See Figure 5,7). The urban wide, 3D visual and aesthetic elements comprising the [Townscape] aspect such as visual experience, views and vistas, skyline protection, identity, and visual connections of districts were well represented in the content of SDDCP, but not as much in IDA [rows 1.1-1.8]. Conversely, the connection of the developments, public facilities, and the capital web to their wider urban and natural context were well represented through IDA's vision of Atlanta [rows 1.9-1.10]. The zoning and regulations concerned with the qualitative and quantitative attributes of the [Urban Form] aspect were emphasized in the content of SDDCP but not as much in IDA [rows 2.1-2.9].

Conversely, the coverage of the lowest four aspects [6-9] in both plans has not reflected their related themes and goals. In SDDCP, the results were mixed; the building regulations and design guidelines elements that address broad design matters comprising the [Development control and architectural character] were well represented [rows 8.1-8.2]. In contrast, the low coverage of the aspects comprising local 3D attributes of the urban environment and detailed design guidance tier did not match the plan goal of controlling public and private development to enhance the character and establish a basis for detailed plans [rows 8.4-8.7; and 9.1-9.7]. Similarly, the low coverage of the elements comprising [Conservation areas and listed buildings], [Public realm] and [Landscape architecture] did not reflect the plan themes namely, Physical Development, Transportation \& Public Facilities, and Community Development, Arts \& Culture, and historic preservation (See Figures 6, 7).

The high percentage of minor coverage level of some aspects, particularly [Conservation areas and listed buildings] is due in part, to the plan's approach in which broader, large-scale design aspects are emphasized, local aspects such as architectural character and landscape architecture are deemphasized, and over-prescriptive control is avoided. These results are consistent with the findings of recent studies regarding current plans' emphasis on accessibility, legibility, vitality, and broader design aspects rather than local aspects, but inconsistent with their emphasis on the public realm.

This mismatch between the design aspects coverage and their related guiding themes implies that the plan's content is inconsistent with the conceptual model in two essential areas. The first is the development of area-wide spatial strategy and public realm to respond to the increasing cultural diversity; the second is the notion of design as an overarching element across scales.

In IDA, the low coverage of the design aspects comprising the intermediate design guidance tier is inconsistent with the conceptual model. Although this discrepancy may have resulted from the plan's scope and goal of creating an area-wide vision that fosters growth and development, it is of crucial importance to integrate the spatial and structural vision with the implementation tools, development projects, and specific regulations and procedures (Palermo \& Ponzini, 2012). The medium coverage of the [Urban Form] as a result, is less likely to effectively meet the plan's goals of achieving smart growth and sustainable urban development [See rows 2.4-2.9, 2.12, 2.15, and Figure 8, 9]. These results are consistent with the findings of recent studies regarding current plans' emphasis on townscape, urban form, and accessibility, but inconsistent with their emphasis on the public realm and sustainability.

Both plans as such were internally inconsistent in translating their guiding themes into high or medium coverage design aspects (See Figures 6 and 8). For instance, Sustainability is the ultimate goal of IDA, the key to Atlanta's vision building and strategic citywide growth and development strategy and, an 
overarching design aspect of SDDCP that is strongly connected to the urban form. However, the low coverage of [sustainable design] and the little to none representation or reference for sustainable urban design through their content may not achieve those goals. Its policies in SDDCP were primarily cursory, and lacking any concrete urban design measures or guidelines including alternative transportation [rows 6.1-6.9] whereas, in IDA, they included broad, 2D urban wide elements such as density, growth management of urban form, and alternative transportation [See Table 2, rows 6.1-6.3]. Also, sustainability is related to two essential guiding themes, landscape ecology, and open space provision (Carmona , 1997b) the first was missing in both plans, whereas the second was covered with medium and low extent in SDDCP and IDA respectively. This mismatch did not conform to the conceptual model, which considers sustainability a crossscale overarching theme that bridges all aspects. To do so, a robust framework for sustainable urban design must link the urban-wide elements and aspects with their counterparts across other scales (Macdonald, 2016; Oliveira \& Pinho, 2010).

The design aspects coverage in both plans was linked to the design guidance tier. The highest two aspects offer strategic/area-wide design guidance, and the lowest three aspects offer detailed design guidance (See Figures 6 and 8). At the intermediate design guidance tier, the link was evident in SDDCP but not in IDA. The elements concerned with quantitative controls of the 3D urban-wide historical character and urban form were well-represented with various degrees of emphasis in both plans but there was a clear omission of the 3D local, detailed, small-scale design elements that are required to create a coherent hierarchical design strategy and infuse design across scales.

These results are due in part, to the plan's approach, which focuses primarily on strategic area-wide vision, the spatial structure, or on physical design rather than local 3D aspects. These results are inconsistent with the conceptual model, which considers design an overarching element across scales, and also inconsistent with the findings of recent studies regarding current plans being dominated by aesthetics and design guidelines that are concerned with the urban form of the city, its buildings, and public realm rather than city-wide visions (Linovski and Loukaitou-Sideris, 2103). 
TABLE 2

THE COVERAGE OF THE DESIGN ASPECTS AND THEIR CONSTITUENT ELEMENTS IN SDDCP AND IDA (PART 1-RANK 1- 4)

\begin{tabular}{|c|c|c|c|c|c|c|c|}
\hline \multirow[b]{3}{*}{ 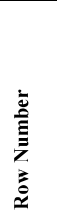 } & \multirow[b]{3}{*}{ DESIGN ASPECTS AND THEIR CONSTITUENT ELEMENTS } & \multicolumn{6}{|c|}{ EXTENT OF COVERAGE } \\
\hline & & \multicolumn{3}{|c|}{ SDDCP } & \multicolumn{3}{|c|}{ IDA } \\
\hline & & 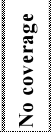 & $\stackrel{5}{\frac{B}{2}}$ & 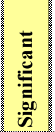 & 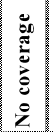 & 章 & 咅 \\
\hline 1 & Townscape (Visual composition of space) & & & & & & \\
\hline 1.1 & Context: Connections among districts and city, visual links to context & & & $\mathbf{x}$ & & & $\mathbf{X}$ \\
\hline 1.2 & Lan dscape: Street furniture, lighting, public art, hard and soft landscape, paving. & & & $\mathbf{X}$ & & & $\mathbf{X}$ \\
\hline 1.3 & Legibility and visibility: Visible framework of public facilities & & & $\bar{X}$ & & & $\mathbf{X}$ \\
\hline 1.4 & Dive rsity: Establishing a variety of visual and spatial compositions & & & $\mathbf{X}$ & & $\mathrm{X}$ & \\
\hline 1.5 & Views and Vistas: View corridors, protecting/emphasizing views as a key to city perception & & & $\mathbf{X}$ & & $\mathrm{X}$ & \\
\hline 1.6 & Identity/Sense of place: maintenance and improvement of dist inct character and unique identity & & & $\mathbf{X}$ & $\mathrm{X}$ & & \\
\hline 1.7 & Skylines prote ction: Relationships between views, topography, and building heights & & & $\bar{x}$ & $\mathrm{X}$ & & \\
\hline 1.8 & Visual Experience: Provision of visually interesting public spaces & & & $\mathbf{X}$ & $\mathrm{X}$ & & \\
\hline 1.9 & Relationship of a development to its site and to its wider setting & & $\mathrm{X}$ & & & & $\bar{x}$ \\
\hline 1.10 & Setting: expression of natural setting, enhancement of natural form & & $\mathrm{X}$ & & & & $\mathbf{X}$ \\
\hline 1.11 & Buffers: treatment of interface between incompatible uses & & $\mathrm{X}$ & & & $\mathrm{X}$ & \\
\hline 1.12 & Stre etscape and Stre e tsce ne: Cont inuity in scale of street scene, building form, building line & & $\mathrm{X}$ & & $\mathrm{X}$ & & \\
\hline 1.13 & Density: plot area ratio, units per acre & $\mathrm{X}$ & & & & & $\mathrm{X}$ \\
\hline 1.14 & Intrusions: Preventing visual intrusions, eradication of eye sores and anomalies & $\mathrm{X}$ & & & & $\mathrm{X}$ & \\
\hline \multirow[t]{3}{*}{1.15} & Landmarks: Visual orientation, focal points policy, landmarks location, uses, and focus views & $\mathrm{X}$ & & & $\mathrm{X}$ & & \\
\hline & Number of coverage types & 3 & 4 & 8 & 5 & 4 & 6 \\
\hline & Percentage of coverage types & 20 & 27 & 53 & 33 & 27 & 40 \\
\hline 2 & Urban Form (Three-dimensional built volume) & & & & & & \\
\hline 2.1 & Character of special areas/places & & & $\overline{\mathbf{X}}$ & & & $\mathbf{X}$ \\
\hline 2.2 & Morphology and grain: Protection and diversity of urban pattern and grain; relation to human scale, block size, plot size & & & $\mathbf{X}$ & & & $\mathbf{X}$ \\
\hline 2.3 & Space system: urban and open space structure & & & $\mathbf{X}$ & & & $\mathbf{X}$ \\
\hline 2.4 & Building height: Controlling building height in relation to streets and spaces & & & $\mathbf{X}$ & $\mathrm{X}$ & & \\
\hline 2.5 & Daylight and sunlight: controlling building siting and sense of enclosure through daylight/sunlight standards, w/massing, density & & & $\mathbf{X}$ & $\mathrm{X}$ & & \\
\hline 2.6 & Dive rsity and pattern of urban grain and block and lot sizes & & & $\overline{\mathbf{X}}$ & $\mathrm{X}$ & & \\
\hline 2.7 & Massing: Controlling building 3D bulk, floor space, harmony with adjacent buildings or spaces & & & $\overline{\mathbf{X}}$ & $\mathrm{X}$ & & \\
\hline 2.8 & Ove rde ve lopment policy: to control bulk, height, density, scale and open space provision, F.A.R., P.C. & & & $\bar{X}$ & $\mathrm{X}$ & & \\
\hline 2.9 & Visual qualities of stree tscapes: Cont inuity of building line and urban grid, road layout, size and enclosure of streets corridors & & & $\mathbf{x}$ & $\mathrm{X}$ & & \\
\hline 2.10 & Block and plot sizes & & $\mathrm{x}$ & & & $\mathrm{X}$ & \\
\hline 2.11 & Richness and visual interest: spatial complexity, variety of spatial experiences & & $\mathrm{X}$ & & & $\mathrm{X}$ & \\
\hline 2.12 & Visual qualities of ope $n$ spaces: Size and enclosure and definition of open spaces and streets corridors & & $\mathrm{X}$ & & $\mathrm{X}$ & & \\
\hline 2.13 & Density allocations in existing are as: Density defined by visual principles, units/acre, or PC & $\mathrm{X}$ & & & & & $\mathbf{X}$ \\
\hline 2.14 & Urban image: manipulation of elements of urban image/form & $\mathrm{X}$ & & & & $\mathrm{X}$ & \\
\hline \multirow[t]{3}{*}{2.15} & Continuity of scale and building form: Relating new development to existing scale, human scale, and pedestrian scale & $\mathrm{X}$ & & & $\mathrm{X}$ & & \\
\hline & Number of coverage types & 3 & 3 & 9 & 8 & 3 & 4 \\
\hline & Percentage of coverage types & 20 & 20 & 60 & 53 & 20 & 27 \\
\hline 4 & Connection and Move ment Ne twork & & & & & & \\
\hline 4.1 & Accessibility to open spaces: for all (pedestrians, motorist, bicyclists) & & & $\mathbf{X}$ & & & $\mathbf{X}$ \\
\hline 4.2 & City-wide and regional access and connections & & & $\bar{X}$ & & & $\overline{\mathbf{X}}$ \\
\hline 4.3 & Prioritizing well-connected network of public spaces & & & $\bar{x}$ & & & $\mathbf{X}$ \\
\hline 4.4 & Public transportation: Cycling/pedestrian/public transport & & & $\overline{\mathbf{X}}$ & & & $\mathbf{x}$ \\
\hline 4.5 & Street and highway network: accommodation of traffic & & & $\bar{x}$ & & & $\mathbf{x}$ \\
\hline 4.6 & Transit systems & & & $\mathbf{x}$ & & & $\mathbf{X}$ \\
\hline 4.7 & Pedestrian ne twork: routes, link to parking, pedestrian -vehicle conflict & & $\mathrm{X}$ & & & & $\mathbf{X}$ \\
\hline 4.8 & Visual and physical permeability & & $\mathrm{X}$ & & & & $\mathbf{X}$ \\
\hline \multirow[t]{3}{*}{4.9} & Parking: accommodation of parking, access to parking & & $\mathrm{X}$ & & & $\mathrm{X}$ & \\
\hline & Number of types & 0 & 3 & 6 & 0 & 1 & 8 \\
\hline & Percentage of Types & 0 & 33 & 67 & 0 & 11 & 89 \\
\hline 5 & Land-use (Mixed-use and dive rsity) & & & & & & \\
\hline 5.1 & Dive rsity: diversity of business types and services, and economic diversity & & & $\mathbf{X}$ & & & $\mathbf{X}$ \\
\hline 5.2 & Mixed land-use: Mixing of uses in urban areas & & & $\mathbf{x}$ & & & $\mathbf{X}$ \\
\hline 5.3 & Provision of adequate and private amenity spaces in urban areas & & & $\mathbf{x}$ & & & $\mathbf{X}$ \\
\hline \multirow[t]{3}{*}{5.4} & Zoning: land-use regulation type and intensity & & & $\mathbf{x}$ & & & $\mathbf{X}$ \\
\hline & Number of coverage types & $\mathbf{0}$ & 0 & 4 & 0 & 0 & 4 \\
\hline & Percentage of coverage types & $\mathbf{0}$ & 0 & 100 & 0 & 0 & 100 \\
\hline
\end{tabular}


TABLE 2

THE COVERAGE OF THE DESIGN ASPECTS AND THEIR CONSTITUENT ELEMENTS IN SDDCP AND IDA (PART 2, RANK 5- 9)

\begin{tabular}{|c|c|c|c|c|c|c|c|}
\hline \multirow{3}{*}{ 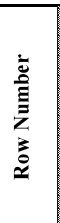 } & \multirow[b]{3}{*}{ DESIGN ASPECTS AND THEIR CONSTITUENT ELEMENTS } & \multicolumn{6}{|c|}{ EXTENT OF COVERAGE } \\
\hline & & \multicolumn{3}{|c|}{ SDDCP } & \multicolumn{3}{|c|}{ IDA } \\
\hline & & 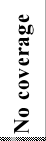 & 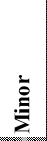 & 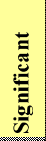 & 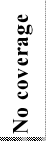 & 竞 & 竞 \\
\hline 3 & Public Realm (The social experience) & & & & & & \\
\hline 3.1 & Connectivity of open space system (parks, green areas, etc) & & & $\mathbf{X}$ & & & $\mathbf{X}$ \\
\hline 3.2 & Improvements of streetscape and streetscene & & & $\mathbf{X}$ & & & $\mathbf{X}$ \\
\hline 3.3 & Vitality: economic vitality, maintenance of downtown vitality & & $\mathrm{X}$ & & & & $\mathbf{X}$ \\
\hline 3.4 & Functional concerns: Parking, servicing, disabled access considerations, and public-private space relationship & $\mathrm{X}$ & & & & & $\mathbf{X}$ \\
\hline 3.5 & Visual qualities of open spaces: richness, lighting, public art, street level & & $\mathrm{X}$ & & & $\mathrm{X}$ & \\
\hline 3.6 & Encouraging legible, comfortable, stimulating and safe streets & $\mathrm{X}$ & & & & $\mathrm{X}$ & \\
\hline 3.7 & Security and design against crime & $\mathrm{X}$ & & & & $\mathrm{X}$ & \\
\hline 3.8 & Sense of community and street level interest & $\mathrm{X}$ & & & & $\mathrm{X}$ & \\
\hline 3.9 & In te gration of Public perceptions of the identity and quality of the built environment into the design strategies & & & $\mathbf{X}$ & $\mathrm{X}$ & & \\
\hline \multirow[t]{3}{*}{3.10} & Social Inte raction: social places, gathering places, opportunities of social interaction & & $\mathrm{X}$ & & $\mathrm{X}$ & & \\
\hline & Number of coverage types & 4 & 3 & 3 & 2 & 4 & 4 \\
\hline & Percentage of coverage types & 40 & 30 & 30 & 20 & 40 & 40 \\
\hline 6 & Sustainable Urban Design & & & & & & \\
\hline 6.1 & Alternative transportation & & $\mathrm{X}$ & & & & $\mathbf{X}$ \\
\hline 6.2 & Growth management: Urban form & & $\mathrm{X}$ & & & & $\mathbf{X}$ \\
\hline 6.3 & Density: Site design and layout & $\mathrm{X}$ & & & & & $\mathbf{X}$ \\
\hline 6.4 & Energy: Energy conservation, orientation, materials & & & $\mathbf{X}$ & $\mathrm{X}$ & & \\
\hline 6.5 & Ecology: Preservation of outstanding natural features, nature conservation & & $\mathrm{X}$ & & $\mathrm{X}$ & & \\
\hline 6.6 & Resource manage ment: avoiding overload on resources, water conservation & & $\mathrm{X}$ & & $\mathrm{X}$ & & \\
\hline 6.7 & Traffic management & & $\mathrm{X}$ & & $\mathrm{X}$ & & \\
\hline 6.8 & Pollution Control: noise reduction & $\mathrm{X}$ & & & $\mathrm{X}$ & & \\
\hline \multirow[t]{3}{*}{6.9} & Macro-climate and micro-climate & $\mathrm{X}$ & & & $\mathrm{X}$ & & \\
\hline & Number of coverage types & 3 & 5 & 1 & 6 & $\mathbf{0}$ & 3 \\
\hline & Percentage of coverage types & 33 & 56 & 11 & 67 & 0 & 33 \\
\hline 7 & Landscape Archite cture & & & & & & \\
\hline 7.1 & Hard landscape layout and planning: Public art, street furniture, lighting & & & $\mathbf{X}$ & & $\mathrm{X}$ & \\
\hline 7.2 & Soft landscape design and layout in open space net work & & $\mathrm{X}$ & & & $\mathrm{X}$ & \\
\hline 7.3 & Soft landscape improvements & $\mathrm{X}$ & & & & $\mathrm{X}$ & \\
\hline 7.4 & Water, trees and greenery & $\mathrm{X}$ & & & $\mathrm{X}$ & & \\
\hline \multirow[t]{3}{*}{7.5} & Buffers & $\mathrm{X}$ & & & $\mathrm{X}$ & & \\
\hline & Number ofcoverage types & 3 & 1 & 1 & 2 & 3 & $\mathbf{0}$ \\
\hline & Percentage of coverage types & 60 & 20 & 20 & 40 & 60 & 0 \\
\hline 8 & Development Control and Architectural Character & & & & & & \\
\hline 8.1 & Building design characte r: Regulations for special areas/districts & & & $\mathbf{X}$ & & $\mathrm{X}$ & \\
\hline 8.2 & Design guidelines to control Building form: height, massing, spacing, scale, and bulk & & & $\mathbf{X}$ & & $\mathrm{X}$ & \\
\hline 8.3 & Zoning and form based code & & $\mathrm{X}$ & & $\mathrm{X}$ & & \\
\hline 8.4 & Architectural style, richness, and visual interest & $\mathrm{X}$ & & & $\mathrm{X}$ & & \\
\hline 8.5 & Building materials and details & $\mathrm{X}$ & & & $\mathrm{X}$ & & \\
\hline 8.6 & Color and texture & $\mathrm{X}$ & & & $\mathrm{X}$ & & \\
\hline \multirow[t]{3}{*}{8.7} & Design Vocabulary: relation of design vocabulary with immediate context & $\mathrm{X}$ & & & $\mathrm{X}$ & & \\
\hline & Number of coverage types & 4 & 1 & 2 & 5 & 2 & 0 \\
\hline & Percentage of coverage types & 57 & 14 & 29 & 71 & 29 & 0 \\
\hline 9 & Conservation Areas and/or Areas of Special Character & & & & & & \\
\hline 9.1 & Conservation of urban form and townscape & & & $\mathbf{X}$ & & & $\mathbf{X}$ \\
\hline 9.2 & Conservation of $\mathbf{C}$ haracte $r$ : Infill development, creation and maitenance of authentic character & & $\mathrm{X}$ & & & & $\mathbf{X}$ \\
\hline 9.3 & Adaptive re-use of historic buildings and areas & & $\mathrm{X}$ & & & $\mathrm{X}$ & \\
\hline 9.4 & Setting: Maintenance of authentic setting & & $\mathrm{X}$ & & $\mathrm{X}$ & & \\
\hline 9.5 & Landmarks and listed buildings: protection and maintenance & $\mathrm{X}$ & & & $\mathrm{X}$ & & \\
\hline 9.6 & Policies for listed buildings: Preservation/conservation/rehabilitation of historic buildings & $\mathrm{X}$ & & & $\mathrm{X}$ & & \\
\hline \multirow[t]{3}{*}{9.7} & Regulatory measures for historic building preservation & $\mathrm{X}$ & & & $\mathrm{X}$ & & \\
\hline & Number of coverage types & 3 & 3 & 1 & 4 & 1 & 2 \\
\hline & Percentage of coverage types & 43 & 43 & 14 & 57 & 14 & 29 \\
\hline
\end{tabular}

70 Journal of Strategic Innovation and Sustainability Vol. 15(4) 2020 
FIGURE 5

EXTENT OF DESIGN ASPECTS COVERAGE OF SAN DIEGO DOWNTOWN COMMUNITY PLAN (SDDCP)

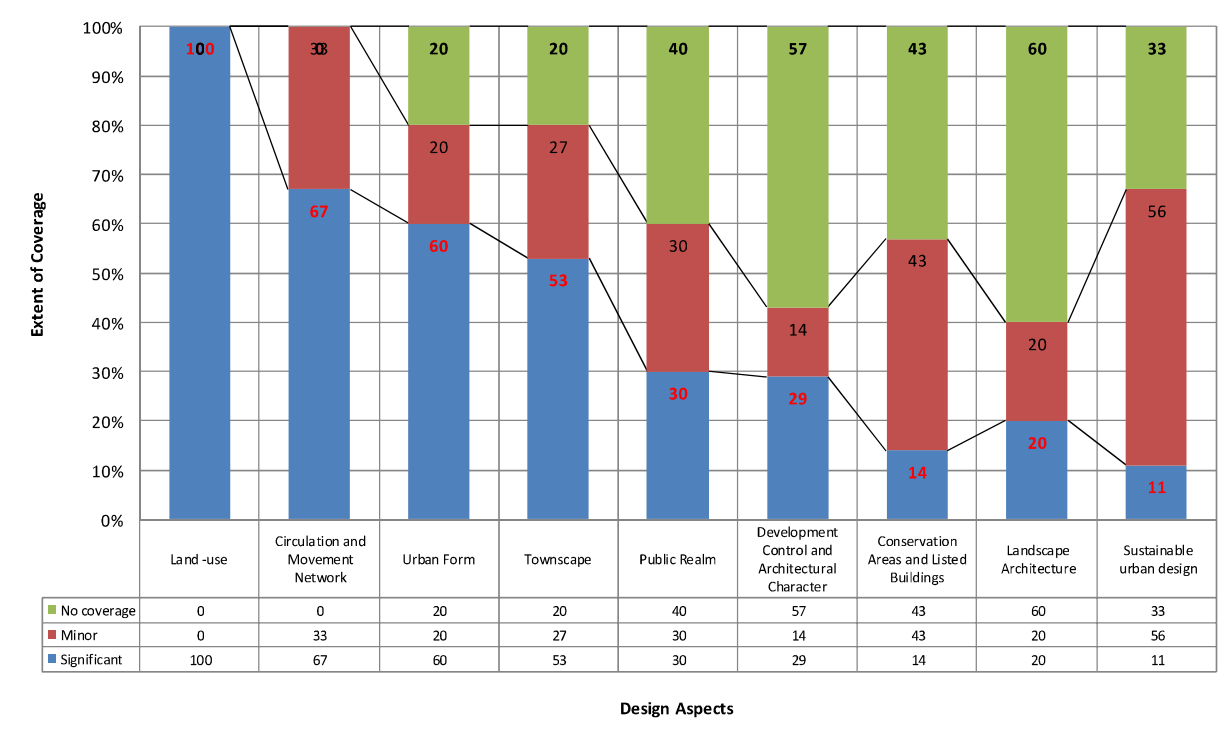

FIGURE 6

DRIVERS, GUIDING THEMES, AND THE EXTENT OF DESIGN ASPECTS COVERAGE, SANDIEGO DOWNTOWN COMMUNITY PLAN (SDDCP)

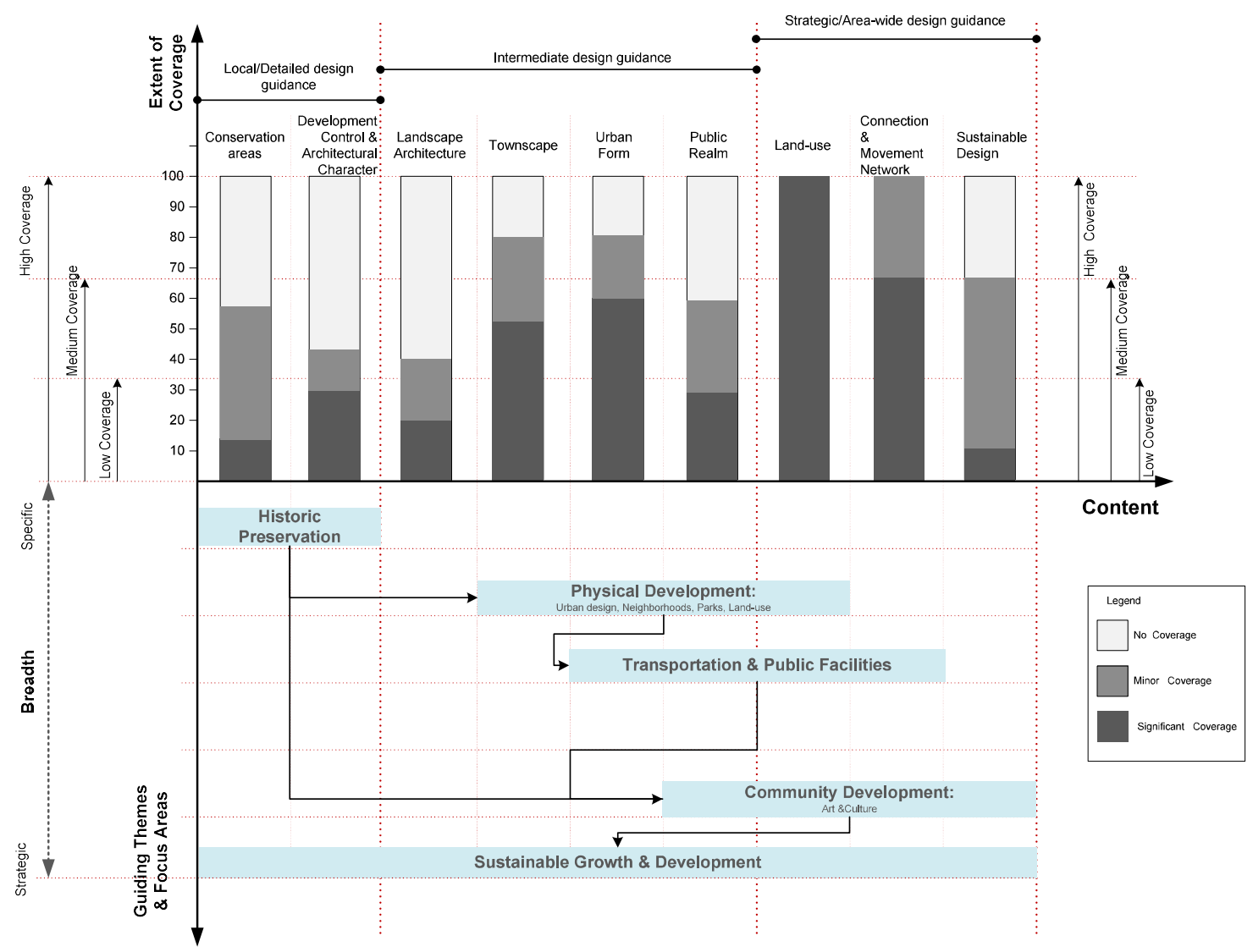


FIGURE 7

DESIGN ASPECTS COVERAGE OF IMAGINE DOWNTOWN ATLANTA (IDA)

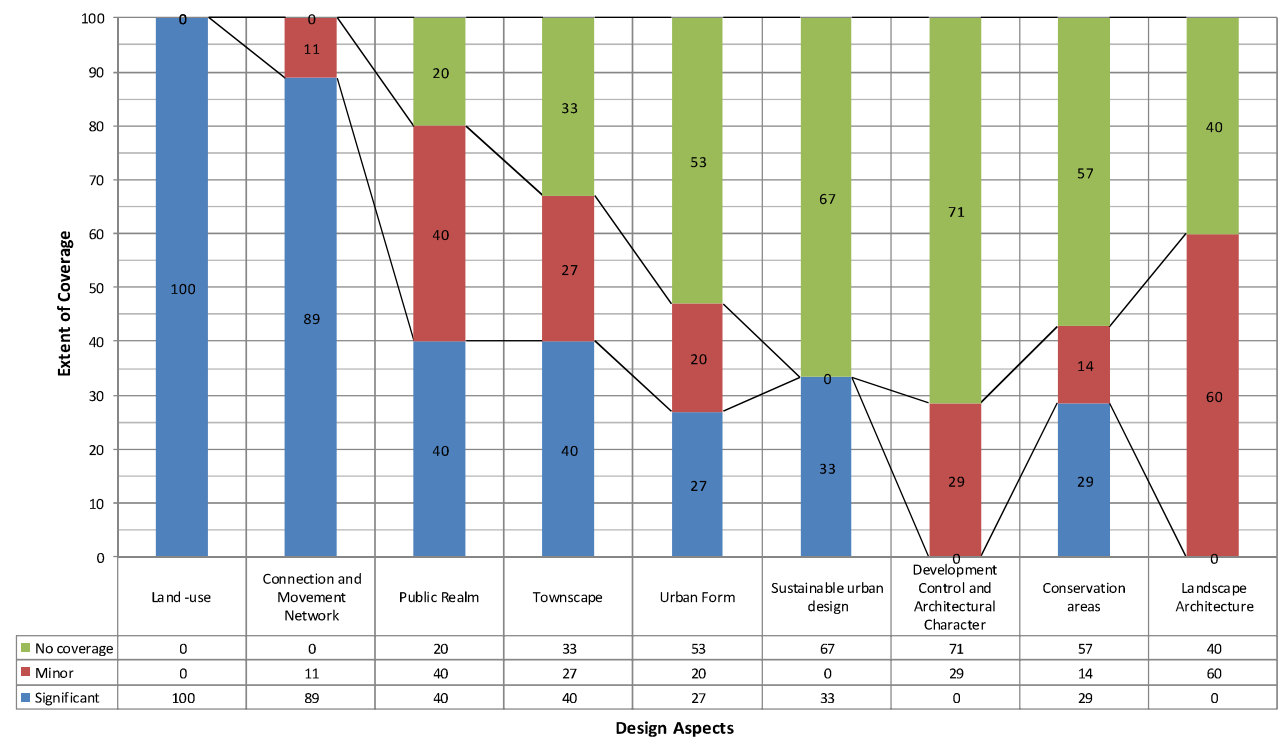

FIGURE 8

DRIVERS, GUIDING THEMES, AND THE EXTENT OF DESIGN ASPECTS COVERAGE, IMAGINE DOWNTOWN ATLANTA (IDA)

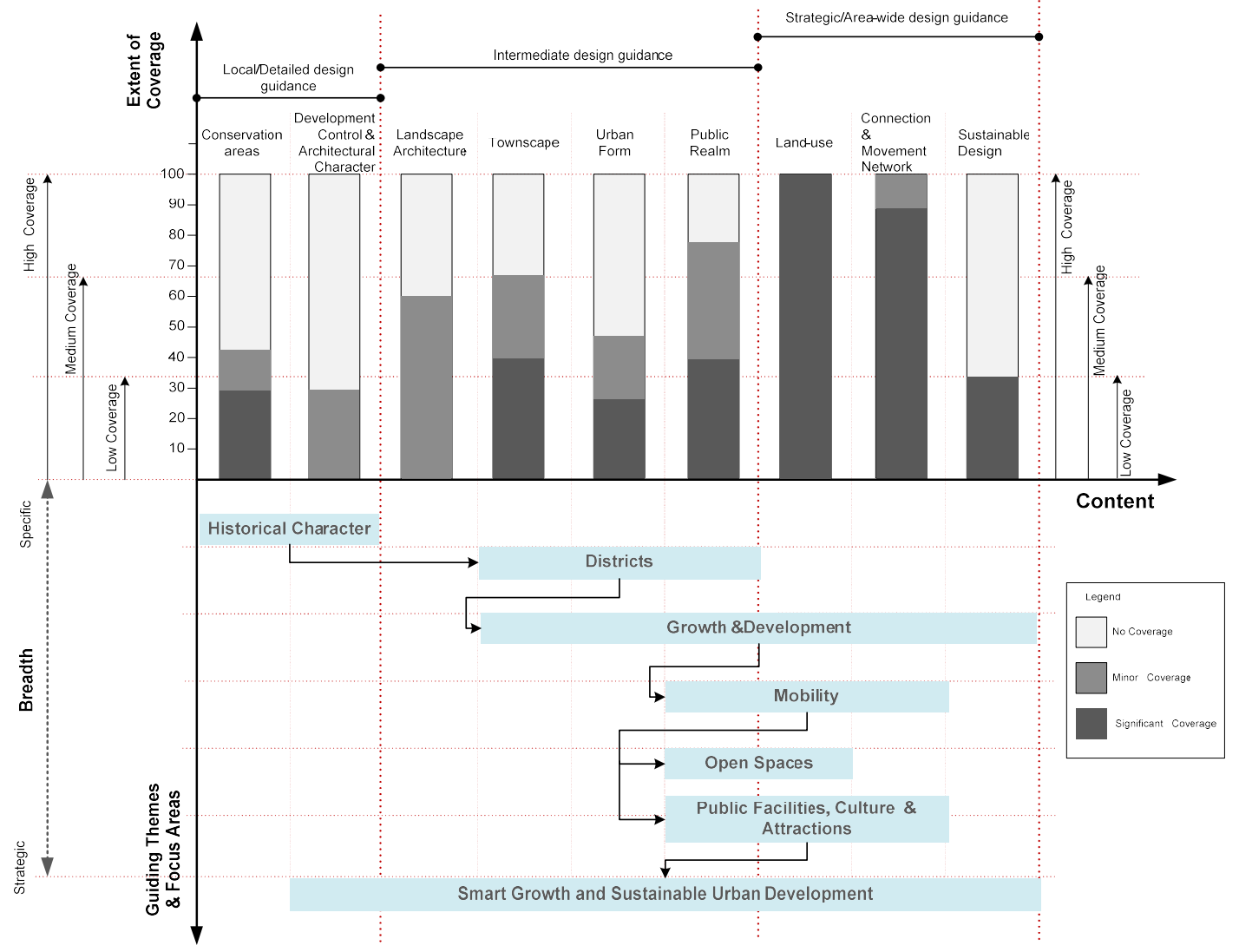

72 Journal of Strategic Innovation and Sustainability Vol. 15(4) 2020 


\section{Comparison of the Plans' Content and Extent of Coverage}

The plans were compared using two criteria: the sum of significant and minor coverage of each aspect (See Figure 9), and the gap between the highest and lowest coverage of each aspect (See Table 3). The results were compared to their counterparts in the Chicago Central Area Plan (CCAP), a recipient of the 2005 national AIA award in the category of Urban Design. It was selected as a benchmark because its guiding themes are comparable to plans' themes, and was analyzed in a previous study using a similar methodology (Al-Douri, 2010; Chappell, 2007; SOM, 2003).

Using the first criterion, the design aspects were sorted in descending order according to the sum of their significant and minor coverage to examine the relation of the minor coverage to the tier of design guidance (See Figure 9). In SDDCP, the minor coverage of the design aspects that constitute the plan focus areas has averaged $18.8 \%$ compared to $37.25 \%$ in the other aspects, whereas those values in IDA were $19.6 \%$ and $25.7 \%$ respectively (See Figure 9). This result provides evidence that the match of the minor and significant coverage of SDDCP's aspects to the plan guiding themes and focus areas was stronger than IDA.

The comparison showed that the values of the significant and minor coverage combined of all SDDCP's design aspects, but Landscape architecture, were either equal to or higher than their IDA's respective aspects, with four distinct types of differences (See Figure). The first [A], the high-difference type (33\%-34\%), consists of two design aspects [Sustainable urban design] and [Urban form] that are at the core of the plans' vision building and strategic city-wide growth and development. These results provide evidence that SDDCP was more consistent in matching its guiding themes and offering hierarchical design guidance. The second [B], the low-difference type (13\%-14\%), consists of three design aspects; one offers intermediate design guidance whereas the others were focused on detailed 3D design guidance.

FIGURE 9

COMPARISON OF DESIGN COVERAGE: SDDCP TO IDA

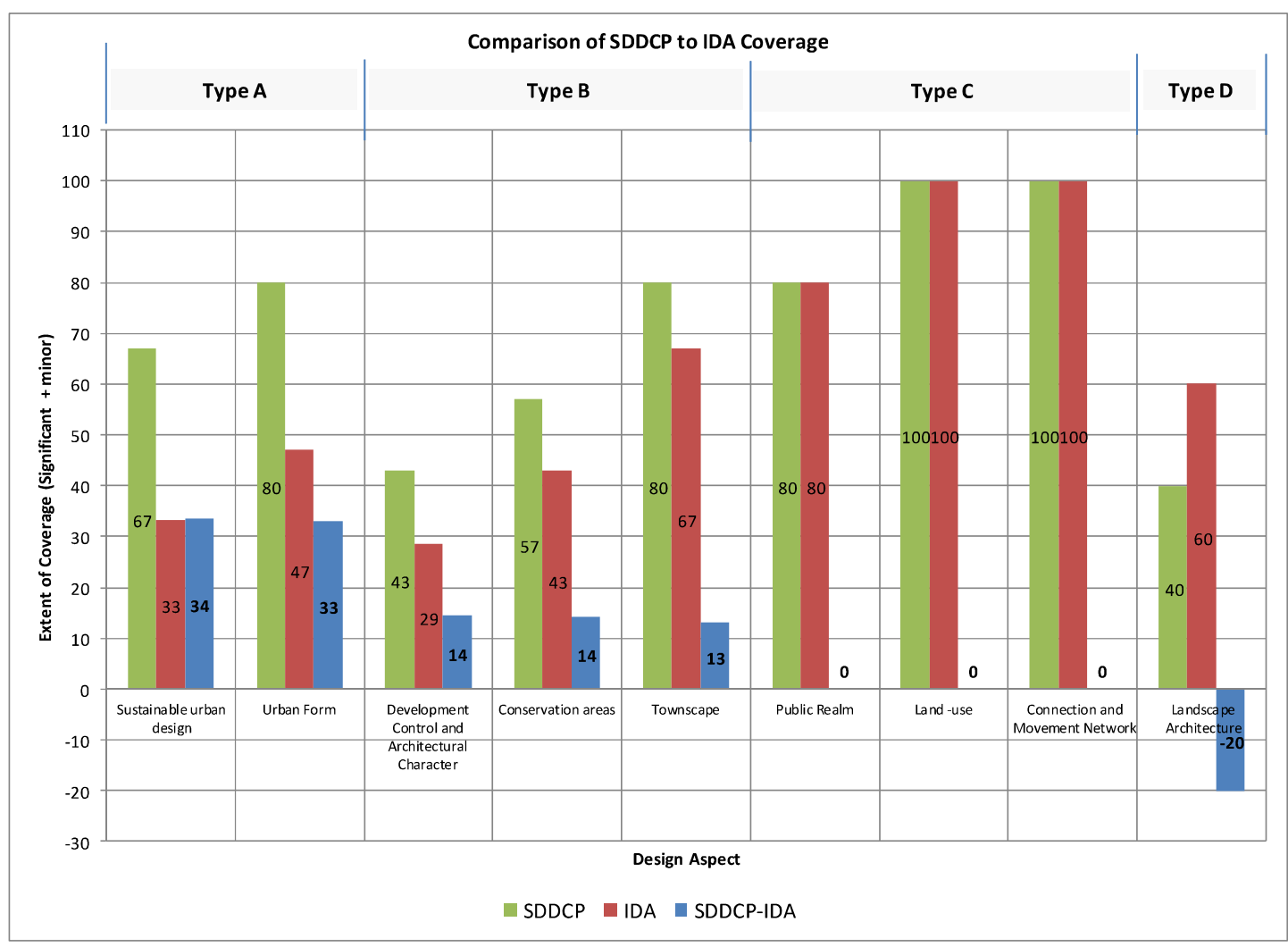


TABLE 3

\section{COMPARISON OF THE EXTENT OF DESIGN ASPECTS COVERAGE OF CCAP, IDA, AND SDDCP}

\begin{tabular}{|c|c|c|c|c|c|c|c|c|c|c|}
\hline \multirow[b]{3}{*}{ No. } & \multirow[b]{3}{*}{ Design Aspects } & \multicolumn{9}{|c|}{ Extent of coverage } \\
\hline & & \multicolumn{3}{|c|}{ CCAP } & \multicolumn{3}{|l|}{ IDA } & \multicolumn{3}{|c|}{ SDDCP } \\
\hline & & 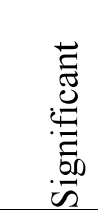 & $\stackrel{5}{\Xi}$ & $\begin{array}{l}8 \\
80 \\
\tilde{\sigma} \\
0 \\
0 \\
0 \\
0 \\
z\end{array}$ & 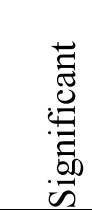 & $\stackrel{\breve{o}}{\Xi}$ & 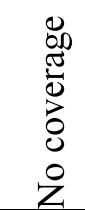 & 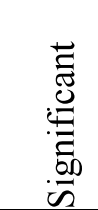 & $\stackrel{\grave{o}}{\Xi}$ & 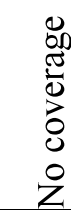 \\
\hline 1 & Sustainable urban design & 33 & 34 & 33 & 33 & 0 & 67 & 11 & 56 & 33 \\
\hline 2 & Circulation and Movement Network & 100 & 0 & 0 & 89 & 11 & 0 & 67 & 33 & 0 \\
\hline 3 & Land -use & 100 & 0 & 0 & 100 & 0 & 0 & 100 & 0 & 0 \\
\hline 4 & Public Realm & 66 & 17 & 17 & 40 & 40 & 20 & 30 & 30 & 40 \\
\hline 5 & Urban Form & 64 & 36 & 0 & 27 & 20 & 53 & 60 & 20 & 20 \\
\hline 6 & Townscape & 66 & 17 & 17 & 40 & 27 & 33 & 53 & 27 & 20 \\
\hline 7 & Landscape Architecture & 43 & 19 & 38 & 0 & 60 & 40 & 20 & 20 & 60 \\
\hline 8 & $\begin{array}{l}\text { Development Control and } \\
\text { Architectural Character }\end{array}$ & 0 & 0 & 100 & 0 & 29 & 71 & 29 & 14 & 57 \\
\hline 9 & $\begin{array}{l}\text { Conservation Areas and Listed } \\
\text { Buildings }\end{array}$ & 34 & 29 & 37 & 29 & 14 & 57 & 14 & 43 & 43 \\
\hline
\end{tabular}

The third $[\mathrm{C}]$, the no-difference type, consists of three high-coverage design aspects that offer strategic/area-wide design guidance. These results are both, conforming to the conceptual model and consistent with the findings of recent studies regarding the emphasis of current urban design plans on urban form, land-use, and public realm. The fourth [D], the negative difference $(-20 \%)$ consists of one design aspect [landscape architecture], which is essential to the plan's goal achievement through the cause and effect relation. The negative difference between the minor and significant coverage in IDA (60\%) compared to $(20 \%)$ in SDDCP, supports the previous findings regarding the plan's approach of focusing on strategic area-wide aspects and being less prescriptive detailed local wide design aspects.

Using the second criterion, the gap between the highest and lowest coverage in IDA $(100 \%-0 \%)$ was slightly wider than SDDCP (100\%- 11\%) which is an indication of a lower extent of coverage and less effective hierarchical design guidance. As such, the SDDCP's content was more consistent than IDA in matching the guiding themes and conforming to the conceptual model regarding hierarchical design guidance.

Although both IDA and CCAP plans were focused more on strategic area-wide growth development than on physical detailed developments, the highest difference between their coverage was at [Townscape], [Urban form], and [Public realm], which are core design aspects comprising the intermediate design guidance tier (See Figure 10).

The highest difference between SDDCP and CCAP coverage was at three design aspects: circulation and movement, public realm, and landscape Architecture (See Figure 11). This difference may reflect their different design approaches where, unlike CCAP's focus on strategic area-wide growth, SDDCP's focus was on physical change, which may explain SDDCP's negative difference in [Development control and architectural character] and the high difference in Circulation movement and public realm.

The results show that the overall coverage of CCAP was higher than both plans. These results are consistent with the previous analytical results regarding IDA's and SDDCP's discrepancies in matching the high-coverage design aspects to the guiding themes and goals. 
FIGURE 10

COMPARISON OF DESIGN COVERAGE: IMAGINE DOWNTOWN ATLANTA (IDA) TO CHICAGO CITY CENTER PLAN (CCAP)

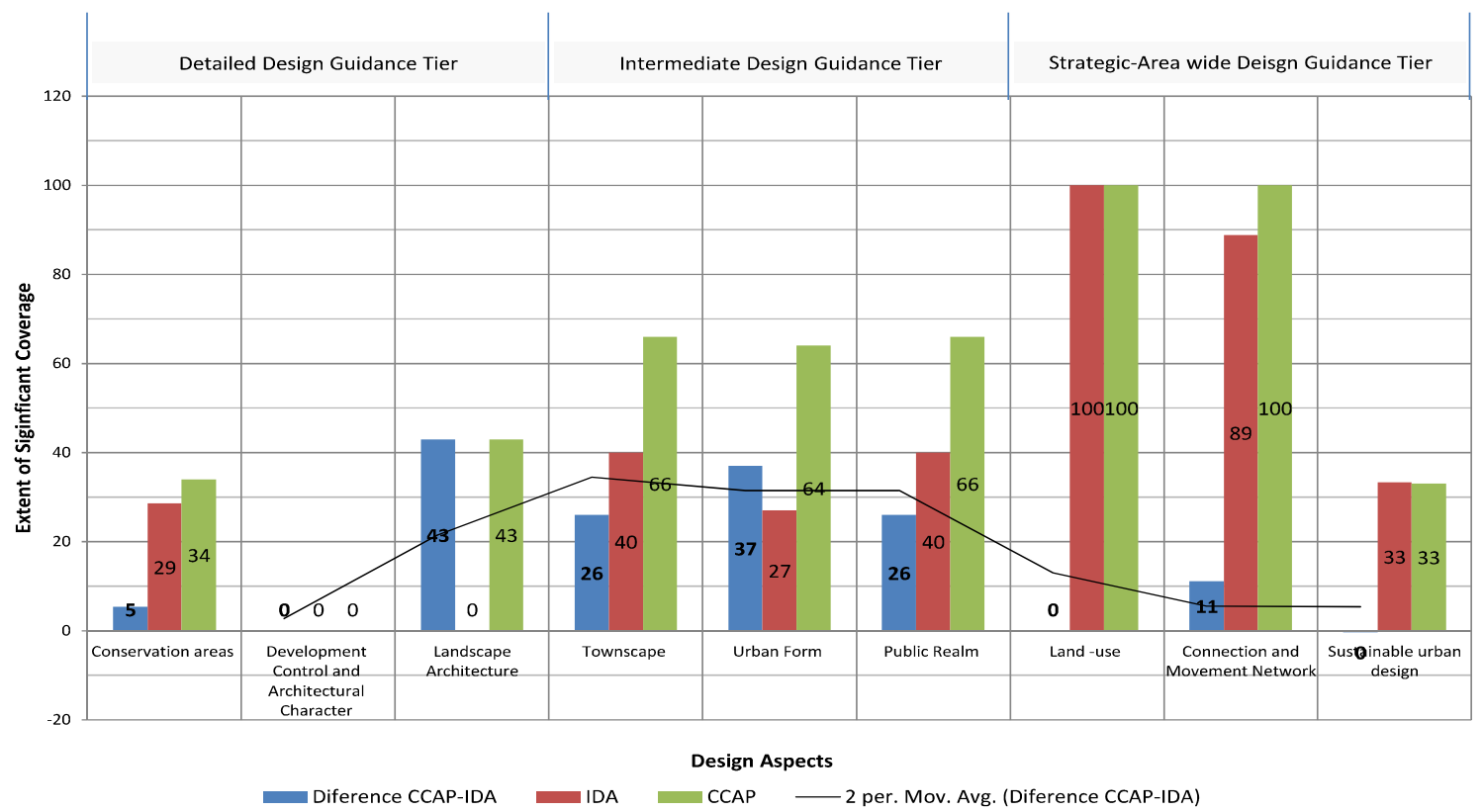

FIGURE 11

COMPARISON OF DESIGN COVERAGE: SAN DIEGO DOWNTOWN COMMUNITY PLAN (SDDCP) TO CHICAGO CITY CENTER PLAN (CCAP)

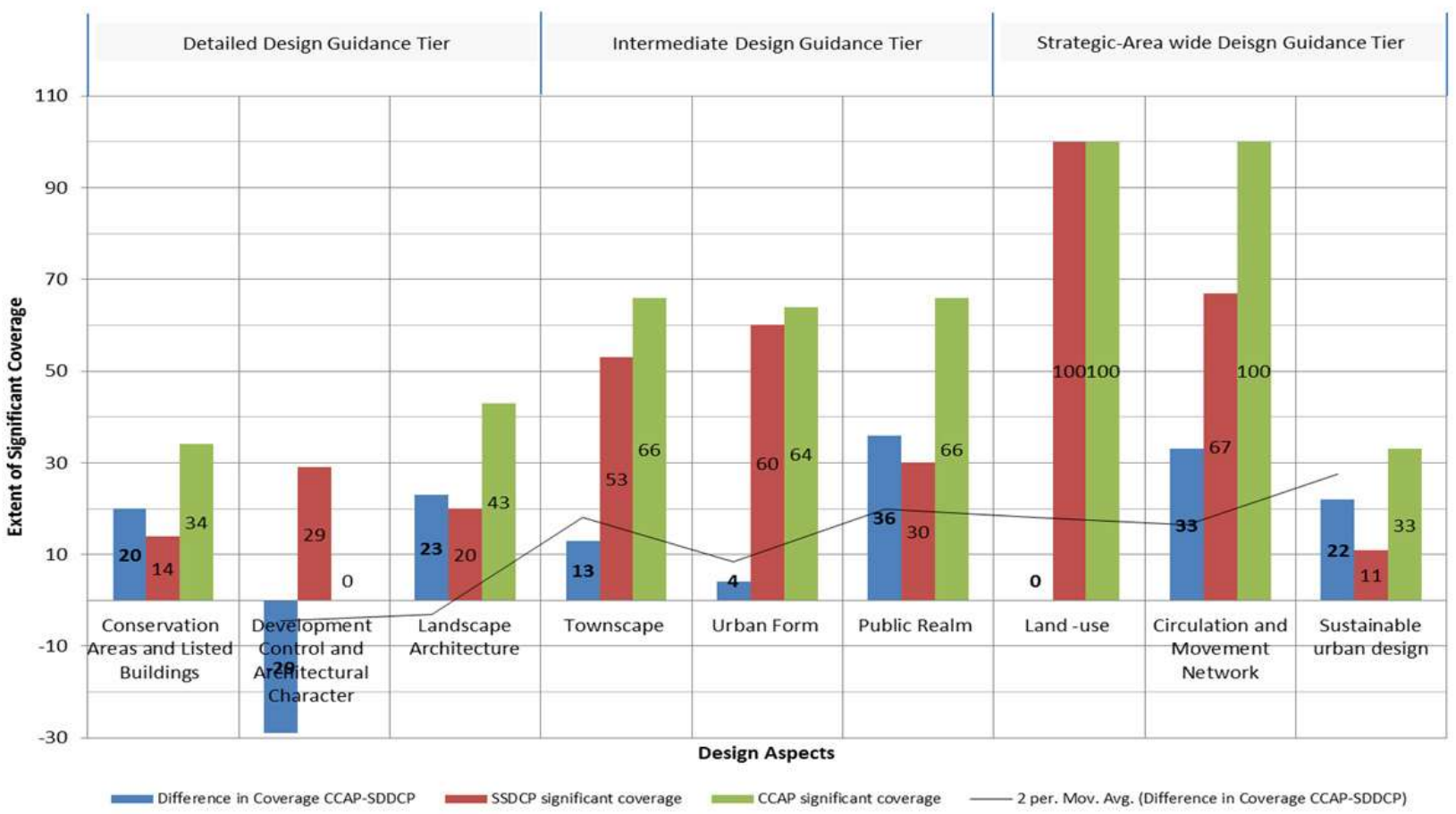




\section{Discussion and Justification of the Empirical Findings}

To address the research questions, the results were compared to the conceptual model, findings of recent studies, and premises collated from literature.

In regards to the first question, the plans differed in how they considered the existing and emerging drivers that are shaping contemporary urban environments. Although most existing drivers such as vitality/mixed-use, accessibility, and physical development and character of the urban form and spatial structure were considered in both plans, the emerging drivers and forces such as community development, culture, health, walkability, safety, and cultural identity were neither explicitly considered nor reflected in any of the plans' themes and policies. The plans' content, for instance, was dominated by elements concerned with the functional and visual attributes and permeability of the circulation network but the significance of its integration with landscape architecture elements to health, walkability, ecology, and amenities remained largely unexplored.

These results are consistent with the findings of recent studies and related literature that described current urban design plans as being limited in scope, scale, and design guidance and failing to address the full scope of existing and emerging drivers. These results are inconsistent with the conceptual model, which suggests that contemporary practice should holistically address existing and emerging drivers.

Regarding the second question, there were discrepancies and inconsistencies in the link of the high extent of design aspects coverage to the plan guiding themes and overall goals. This link was more evident in SDDCP than in IDA in two aspects: sustainable urban design and urban form. These results are in line with the findings of a recent study of current urban design plans (Linovski and Loukaitiu-Sideris, 2013) regarding the mismatch between the plan's content and its goals and guiding themes.

As for the third question, the extent of coverage was linked to the tier of design guidance. The high and low extent of coverage were linked to strategic and detailed design guidance respectively, whereas, at the intermediate design guidance tier, the link was evident in SDDCP but not in IDA. This link may indicate the plan's approach of focusing on the development of a strategic, area-wide spatial strategy for growth and development and avoiding stifling creativity, detailed design guidance, and architectural character.

The high/medium coverage of $2 \mathrm{D}$ urban-wide design elements at the strategic level was largely absent at the 3D local, detailed level where guidelines would be useful for providing an overall vision for development. These differences may reflect the "reactive mode" (Punter and Carmona 1997b) and the trend of emphasizing two-dimensional, land-use strategic, capital web, infrastructure elements, and aspects. This approach does not conform to the conceptual model and may not establish the hierarchical design guidance required to holistically control and shape the urban environment across scales.

The results showed that in SDDCP, the overall extent of coverage was higher, and the content and hierarchy of design guidance was richer and broader than IDA. Each plan appeared to have adopted a different approach to addressing the existing and emerging drivers and achieving its goals. On one hand, IDA reflected the strategic approach, which is primarily focused on shaping the urban form and urban infrastructure with an emphasis on a few design aspects that are central to the role of urban design. On the other hand, SDDCP reflected the physical design approach, which offered a broader plan content that consists of a wide range of design aspects but with special emphasis on a large scale. As a benchmark, CCAP has more extensively covered its design aspects and has more consistently reflected its guiding themes than both plans.

Thus, both plans involved internal inconsistencies as well as inconsistencies with the conceptual model in how it related the plan's substantive elements to its goals and tiers of the design hierarchy. Those inconsistencies may negatively affect the effectiveness of the comprehensive, cross-scale design control strategy that is essential to achieve its goals. According to the conceptual model, the drivers should translate into design themes, focus areas, and high-coverage design aspects and policies that should be implemented through the three-tier hierarchical design control system. The translation process, however, has only been partially achieved due to two reasons. The first is the medium or low extent of coverage of the aspects and elements that are related to those guiding themes, in particular, those that 
comprise intermediate and local design guidance; second, the approach to design development which tends to avoid stifling with prescriptive design guidance in favor of performance guidance.

\section{CONCLUSIONS}

This study has examined key substantive elements of two urban design plans in an attempt to assess the extent to which their relationship was consistent and conforming to the conceptual model. The study has provided complementary results; it highlighted the plans' internal inconsistencies and the plans' inconsistencies with the conceptual model and explained how those inconsistencies and discrepancies affect the fulfillment of the plan goals. Although two cases cannot support general conclusions, the findings represent a data point that complements the findings of recent studies, in particular, Linovski \&Loukaitiu-Sideris (2013) and Southworth (1989).

Current dynamics in the socio-cultural landscape of the urban environment suggest that urban designers examine new approaches, methods, and concepts of urban design. While most existing drivers were emphasized in both plans, the emerging drivers and forces were neither explicitly emphasized nor reflected in any of the plans' themes and policies. These results suggest adopting a comprehensive, holistic design approach, which expands the scope and scale of the drivers and forces that plans typically consider to include the emerging ones such as cultural identity, sense of community, place-making, community development, health, and walkability.

However, to consider those drivers comprehensively without tailoring them to the local conditions and without strong professional and community support may be impractical and may lead to their failure. The process should be carefully tailored to the locally important issues and conditions after a thorough assessment of the characteristics of the urban environment. To do so, local planning and design agencies need to address the inadequacy of design development and delivery methods and utilize advanced information technology through the design development process. The potential contribution of these factors to these inconsistencies should be investigated in future research.

The content analysis revealed a major failing of urban design policies and that is their general failure to consider design at the level of neighborhood or district or as something operating beyond the level of downtown. The plans' content was focused primarily on urban-wide planning, land-use, and development related issues, whereas a clear urban design strategy and vision were lacking in both plans. This contrasts sharply with the quantitative standards that were expressed and prescriptively formulated within the broad, urban-wide strategies. These results support the literature premise regarding the dominance of twodimensional land-use planning over considerations of the three-dimensional urban form (Punter, 2010; Punter \& Carmona, 1997b). They are an indication of the reactive mode of the planning agencies, and their emphasis on the establishment of spatial strategies that direct broad patterns of urban growth and infrastructure investment.

Urban Design needs to be coordinated on a hierarchical scale through which the guiding themes and focus areas be translated into design aspects tailored to the local characteristics. With the shift in urban design practice away from large-scale public sector redevelopment projects, urban design plans had to use such hierarchical design control to achieve the public objective. Careful cross-referencing of policies and supplementary design guidance is particularly important to ensure comprehensive coverage of design issues and to ensure that designers and controllers consider the wide range of concerns that constitute the design ethos of the planning authority. 


\section{REFERENCES}

AIA. (2005, November 15). The Urban Design Process: Creating and achieving a vision in Best Practices. Retrieved from http://www.aia.org/SiteObjects/files/BP_17_06_01.pdf

AIA. (2008). Communities by Design Built Works: Architects Demonstrate the Value of Community Design: A Civic Vision for Turnpike Air Rights Boston. Massachusetts Boston, MA. Retrieved March 17, 2008, from http://www.aia.org/csp goody turnpike,

Al-Douri, F. (2006). Impact of utilizing 3D Digital Urban Models on the Design Content of Urban Design Plans in US Cities. Ph.D. Thesis, College of Architecture, Texas A\&M University, College Station, Texas

Al-Douri, F. (2010). The impact of 3D modeling function usage on the design content of urban design plans in US cities. Environment and Planning B: Planning and Design, 37(1), 75-98.

Al-Douri, F. (2013). Assessment of the methods and extents of the usage of urban modeling in urban design practice in US cities. Environment and Planning B: Planning and Design, 40(3), 523-549.

Barnett, J. (1982). An Introduction to Urban Design. New York: Harper and Row.

Batty, M. (2007). Planning support systems: progress, predictions, and speculations in the shape of things to come. Centre of Advanced Spatial Analysis. University College London, Working Paper no. 122 .

Biddulph, M. (2012). The Problem with Thinking about or for Urban Design. Journal of Urban Design, $17(1), 1-20$.

Boyatzis, R. E. (1998). Transforming Qualitative Information: Thematic analysis and code development. Thousand Oaks, US: Sage Publication.

Boyko, C. T., Cooper, R., Davey, C. L., \& Wootton, A. B. (2006). Addressing sustainability early in the urban design process. Management of Environmental Quality: An International Journal, 17(6), 689-706.

Brown, L. J., \& Dixon, D. (2014). Urban Design for an Urban Century: Shaping More Livable, Equitable, and Resilient Cities ( $2^{\text {nd }}$ Edition). New Jersey, US: John Wiley \& Sons, Inc.

Brown, L. J., Dixon, D., \& Gillham, O. (2009). Urban Design for an Urban Century: Placemaking for people. New Jersey, US: John Wiley \& Sons, Inc.

Bullivant, L. (2012). Masterplanning Futures. Oxon, UK: Routledge.

CABE. (2005). Making design policy work: How to deliver good design through your local development framework. London, UK: The Commission for Architecture \& the Built Environment, CABE.

Carmona, M. (2014). The Place-shaping Continuum: A Theory of Urban Design Process. Journal of Urban Design, 19(1), 2-36.

Carmona, M., Punter, J., \& Chapman, D. (2002). From Design Policy to Design Quality. Royal Town Planning Institute (RTPI) London, UK: Thomas Telford.

Center City Development Corporation (CCDC). (2006). San Diego Downtown Community Plan: Rising on the Pacific. Retrieved June 2, 2001, from

http://www.ccdc.com/images/stories/downloads/planning/plans/sdcp-all.pdf

Central Atlanta Progress (CAP). (2009). Imagine Downtown: ENCORE 2009 Update: Envisioning

Central Atlanta's Future. Retrieved May 27, 2010, from

http://www.atlantadowntown.com/_files/docs/imagineencorereport_web.pdf

Chappell, J. (2007). The Chicago central area plan. TOPOS, (58), 81-83.

Chen, F. (2016). The Design Dimension of China's Planning System: Urban Design for the Development Control. International Planning Studies, 21(1), 81-100.

Childs, M. C. (2010). A spectrum of urban design roles. Journal of Urban Design, 15(1), 1-19.

City of Portland. (2007). Central Portland Plan: Urban Design Assessment. Contemporary Case Studies (unnumbered). Retrieved January 24, 2009, from

http://www.portlandonline.com/shared/cfm/image.cfm?id=152589

78 Journal of Strategic Innovation and Sustainability Vol. 15(4) 2020 
Cooper, R., \& Boyko, C. (2010). How to Design A City in Five Steps: Exploring VivaCity2020's process and tools for urban design decision making? Journal of Urbanism: International Research on Placemaking and Urban Sustainability, 3(3), 253-273.

Cullingworth, J. B., \& Caves, R. W. (2009). Planning in the USA: policies, issues, and processes $\left(3^{\text {rd }}\right.$ Edition). New York, US: Routledge.

DETR, Commission for Architecture \& the Built Environment. (2000). By design: urban design in the planning system: towards better practice. London: Thomas Telford.

Devillis, R. (1991). Scale Development; Theory and applications. US, Thousand Oaks: Sage Publications.

Dyett and Bhatia. (n.d.). San Diego Downtown. Retrieved April 21, 2010, from http://www.dyettandbhatia.com/sandiego ud.htm

Feliciotti, A., Romice, O., \& Porta, S. (2015, July 13-16). Masterplanning for change: lessons and directions. In M. Macoun \& K. Maier, Proceedings of the $29^{\text {th }}$ Annual AESOP Congress, Definite Space-Fuzzy Responsibility (pp. 3051-3065). Prague, CZ.

Gosling, D., \& Gosling, M. (2003). Evolution of American urban design: A chronological approach. UK: Wiley-Academy.

Harfield, S. (2010). Urban Design as Social Benefit: Thinking beyond Formality and Physicality. ANZAPS 2010 Conference Proceedings, pp. 53-64.

Headman, R., \& Jaszewski, A. (1984). Fundamentals of urban design. Washington, D.C, American Planning Association: Planners Press.

Hoppenfeld, M. (1960). The role of design in city planning: With reference to center-city Philadelphia. Journal of the American Institute of Planners, 26(2), 98-103.

Hu, R. (2013). Urban Design Plans for Downtown San Francisco: A Paradigm Shift? Journal of Urban Design, 18(4), 517-533.

Inam, A. (2011). From Dichotomy to Dialectic: Practicing Theory in Urban Design. Journal of Urban Design, 16(2), 257-277.

Jaskiewicz, I. T. (2013). Towards a Methodology for Complex Adaptive Interactive Architecture. Ph.D. Dissertation, Department of Architecture, Technical University of Delft, Netherlands.

Kelbough, D. (1994). Urban Design Teaching and Practice, A Quiet Revolution. Places, A Quarterly Journal of Environmental Design, 9(1), 72-73.

Krippendorff, K. (2004). Content analysis: an introduction to its methodology ( $2^{\text {nd }}$ edition). US, Thousand Oaks: Sage publications.

Kunze, A., Burkhard, R., Gebhardt, S., \& Tuncer, B. (2012). Visualization and Decision Support Tools in Urban Planning. In S.M. Arisona, G. Aschwanden, J. Halatsch, \& P. Wonka (Eds.), Digital Urban Modeling and Simulation (vol. 242, pp. 279-298). Springer, Heidelberg.

Lang, J. (1994). Urban Design: The American experience. NY: VanNostrand Reinhold.

Lang, J. (2005). Urban Design: A Typology of Procedures and Products. MA, US: Architectural Press.

Laurian, L., Crawford, J., Day, M., Kouwenhoven, P., Mason, G., Ericksen, N., \& Beattie, L. (2010). Evaluating the outcomes of plans: theory, practice, and methodology. Environment and Planning B: Planning and Design, (37), 740-757.

Lehmann, S. (2006). Towards a Sustainable City Centre: Integrating Ecologically Sustainable Development (ESD) Principles into Urban Renewal. Journal of Green Building, 1(3), 83-104.

Lim, C. J., \& Ed, L. (2010). Smart-Cities and Eco-Warriors. New York and London: Taylor \& Francis.

Linovski, O., \& Loukaitou-Sideris, A. (2013). Evolution of Urban Design Plans in the United States and Canada: What Do the Plans Tell Us about Urban Design Practice? Journal of Planning Education and Research, 33(1), 66-82.

Llewelyn-Davis \& Alan Baxter \& Associates. (2002). Urban Design Compendium (UDC). London, UK: The English Partnership and the Housing Corporation.

Lloyd-Jones, T. (2006). Globalizing Urban Design. In M. Moor \& J. Rowland (Eds.), Urban Design Futures (pp. 29-37). London, Routledge.

Loukaitou-Sideris, A. (2012). Addressing the Challenges of Urban Landscapes: Normative Goals for Urban Design. Journal of Urban Design, 17(4), 467-484. 
Loukaitou-Sideris, A., \& Banerjee, T. (2011). Downtown urban design. In T. Banerjee \& A. LoukaitouSideris (Eds.), Companion to urban design (pp. 345-355). Oxon, UK: Routledge.

Macdonald, E. (2016). The planning dimension of sustainable urban design. Journal of Urban Design, 21(1), 43-45.

Marshall, S. (2015). Refocusing urban design as an integrative art of place. Proceedings of the ICEUrban Design and Planning, 168(1), 8-18

Matthew, C., Steve, T., Tim, H., \& Taner, O. (2010). Public Places-Urban Spaces; The dimensions of urban design ( $2^{\text {nd }}$ Edition). Burlington: Architectural Press.

Moor, M., \& Rowland, J. (Eds.). (2006). Urban Design Futures. UK, London: Routledge.

Mugavin, D. (1992). Urban design and the physical environment: the planning agenda in Australia. Town Planning Review, 63(4), 403-413.

Norton, R. K. (2008). Using content analysis to evaluate local master plans and zoning codes. Land Use Policy, 25(3), 432-454.

Oliveira, V., \& Pinho, P. (2010). Evaluation in urban planning: Advances and prospects. Journal of Planning Literature, 24(4), 343-361.

Palermo, P. C., \& Ponzini, D. (2012). At the crossroads between urban planning and urban design: Critical lessons from three Italian case studies. Planning Theory \& Practice, 13(3), 445-460.

Paterson, E. (2012). Urban Design and the National Planning Policy Framework for England. Urban Design International, 17(2), 144-155.

Punter, J. (1999). Design guidelines in American cities: a review of design policies and guidance in five west coast cities. UK: Liverpool University Press.

Punter, J. (2007). Developing Urban Design as Public Policy: Best Practice Principles for Design Review and Development Management. Journal of Urban Design, 12(2), 167-202.

Punter, J. (2010). The Vancouver Achievement: Urban planning and design. Vancouver, Canada: UBC Press.

Punter, J., \& Carmona, M. (1997a). Design Policies in Local Plans. Recommendations for Good Practice. Town Planning Review, 68(2), 165-193.

Punter, J., \& Carmona, M. (1997b). The Design Dimension of Planning: Theory, Content, and Best Practice for Design Policies. London, UK: E\&FN Spon.

Punter, J., \& Carmona, M., (1996). Urban Design Policies in English Local Plans: Content and Prescription. Urban Design International, 1(3), 201-234.

Punter, J., Carmona, M., \& Platts, A. (1994). The design content of development plans. Planning Practice and Research, 9(3), 199-220.

Rachel, K. (2011). Tianjin Eco-city. In K. Rachel (Ed.), Rising in the East: Contemporary New Towns in Asia (pp. 72-79). Amsterdam: SUN.

Rowley, A. (1994). Definitions of Urban Design: The Nature and Concerns of Urban Design. Planning Practice and Research, 9(3), 179-198.

SOM (Skidmore, Owings \& Merrill LLP). (2003). Chicago central area plan. Retrieved March 21, 2005, from http://www.cityofchicago.org/city/en/depts/dcd/supp_info/central_area_plandraft.html

Southworth, M. (1989). Theory and Practice of Contemporary Urban Design. Town Planning Review, 60(4), 369-402.

Southworth, M., \& Southworth, S. (1973). Environmental quality in cities and regions: A review of analysis and management of environmental quality in the United States. Town Planning Review, $44(3), 231-53$

Strauss, A., \& Corbin, J. (1998). Basics of Qualitative Research: techniques and procedures for developing grounded theory ( $2^{\text {nd }}$ edition). Thousand Oaks, US: Sage publications.

Turner, S. (1993). The design content of development briefs: a critical evaluation. M.Sc. Dissertation, Department of Town and Country Planning, University of Reading, UK.

Turner, S. (1994). Improving the content and utility of design briefs. Planning Practice and Research, 9(3), 289-310.

80 Journal of Strategic Innovation and Sustainability Vol. 15(4) 2020 
Urban Task Force (UTF). (1999). Towards an Urban Renaissance: Final Report of the Urban Task Force. London, UK: Spon Press.

Waldheim, C. (2013). Landscape as Urbanism. In M. Larice \& E. Macdonald (Eds.), The Urban Design Reader ( $2^{\text {nd }}$ Edition, pp. 534-543). New York: Routledge.

Weber, R. (1985). Basic Content Analysis ( $2^{\text {nd }}$ Edition, Volume 49). Thousand Oaks, US: Sage Publication.

Zammit, A. (2014). Unlocking Policy Documents: Policy analysis in urban design. In M. Carmona (Ed.), Explorations in Urban Design: An urban design research primer. Ashgate Publishing, Ltd. 